\title{
Molecular Structure, NMR, HOMO, LUMO, and Vibrational Analysis of O-Anisic Acid and Anisic Acid Based on DFT Calculations
}

\author{
R. Mathammal, ${ }^{1}$ N. Jayamani, ${ }^{2}$ and N. Geetha ${ }^{3}$ \\ ${ }^{1}$ Department of Physics, Sri Sarada College for Women (Autonomous), Salem 636016, India \\ ${ }^{2}$ Department of Physics, Vivekanandha College of Arts and Sciences (W), Namakkal 637205, India \\ ${ }^{3}$ Department of Physics, Bharathiyar Arts \& Science College (W), Salem 636112, India
}

Correspondence should be addressed to N. Jayamani; njayamaniravi@yahoo.co.in

Received 1 May 2013; Accepted 14 July 2013

Academic Editor: Renata Diniz

Copyright (c) 2013 R. Mathammal et al. This is an open access article distributed under the Creative Commons Attribution License, which permits unrestricted use, distribution, and reproduction in any medium, provided the original work is properly cited.

This work deals with the vibrational spectroscopy of O-Anisic acid (OAA) and Anisic acid (AA). The fundamental vibrational frequencies and intensity of vibrational bands were evaluated using density functional theory (DFT) with standard B3LYP/6-31G** method and basis set combinations. The vibrational spectra were interpreted, with the aid of normal coordinate analysis based on a scaled quantum mechanical force field. The infrared and Raman spectra were also predicted from the calculated intensities. The effects of carbonyl and methyl substitutions on the structure and vibrational frequencies have been investigated. Comparison of simulated spectra with the experimental spectra provides important information about the ability of the computational method to describe the vibrational modes. The ${ }^{13} \mathrm{C}$ and ${ }^{1} \mathrm{H}$ NMR chemical shifts of the DFA and CA molecules were calculated using the gauge-invariant-atomic orbital (GIAO) method in DMSO solution using IEF-PCM model and compared with experimental data.

\section{Introduction}

Aromatic acids have all the properties characteristic of the carboxylic acids of the aromatic series. In medicine, aromatic acids are employed as weak antiseptics, and their salts as carriers of specific cations [1]. Benzoic acid derivatives substituted by hydroxyl group or ether containing oxygen atom have active bacteriostatic and fragrant properties. They are typically used in pharmaceutical and perfumery industry.

Anisic acid or methoxy benzoic acid is an organic compound which is a carboxylic acid. Anisic acid is a part of cresol class antiseptic compounds. It is also used as an insect repellent. Anisic acid and its derivatives are also widely used in chemical reaction as intermediates to obtain target materials such as dyes, pharmaceuticals, perfumes, photoinitiators, and agrochemicals. O-Anisic acid is used in organic synthesis and antiseptic disinfectant [2].

The vibrational assignments of the compounds can be proposed on the basis of the wavenumber agreement between the computed harmonics and the observed fundamentals.
Quantum chemical computational methods have proven to be an essential tool for interpretations and prediction of vibrational spectra $[3,4]$. A significant advent in this area was made by the scaled quantum mechanical (SQM) force field method [5-8]. In the SQM approach, the systematic errors of the computed harmonic force field are corrected by a few scale factors which were found to be well transferable between chemically related molecules $[4,9-11]$.

In this study, we recorded FTIR and FT-Raman spectra and calculated the vibrational frequencies of O-Anisic acid and Anisic acid in the ground state to distinguish fundamentals from experimental vibrational frequencies and geometric parameters using DFT/B3LYP (Becke3-Lee-yangParr) method. Natural bond orbital (NBO) analysis of the title molecules was also carried out. In addition, the gaugeinvariant-atomic orbital (GIAO) ${ }^{13} \mathrm{C}$ and ${ }^{1} \mathrm{H}$ chemical shifts calculations of the title compounds were calculated by using B3LYP/6-31G ${ }^{* *}$ basis set [12]. The calculated quantum chemical parameters are $E_{\mathrm{HOMO}}, E_{\mathrm{LUMO}}, \Delta E$, and those parameters that give valuable information about the reactive behavior 
such as chemical potential $\left(P_{i}\right)$, global hardness $(\eta)$, and the softness $(\sigma)$ [13]. A detailed quantum chemical study will aid in making definite assignments to fundamental normal modes of OAA and AA to clarify the experimental data for these important molecules.

\section{Experimental}

The pure crystalline samples of OAA and AA were obtained from Lanchester chemical company, UK, and used without further purification for the spectral measurements. The room-temperature Fourier-transform (FT) infrared spectra of the title compounds were measured in the region 4000$400 \mathrm{~cm}^{-1}$ at a resolution of $\pm 1 \mathrm{~cm}^{-1}$ using BRUKER IFS$66 \mathrm{~V}$ Fourier-transform spectrometer, equipped with an MCT detector, a KBr beam splitter, and a globar source. The FTRaman spectra were recorded on the same instrument with an FRA-106 Raman accessory in the region $4000-50 \mathrm{~cm}^{-1}$. The 1064-nm line of a Nd:YAG laser was used as excitation source, and the laser power was set to $200 \mathrm{mw}$.

The ${ }^{1} \mathrm{H}$ and ${ }^{13} \mathrm{C}$ NMR spectra were taken in $\mathrm{CDCl}_{3}$, and DMSO- $d_{6}$ solution and all signals were referenced to TMS on a BRUKER FT-NMR spectrometer. All NMR spectra were measured at room temperature.

\section{Computational Details}

All the calculations were performed by using Gaussian 03 program [14] package on the personal computer. The Becke's three-parameter hybrid density functional, B3LYP, was used to calculate both harmonic and anharmonic vibrational wavenumbers with $6-31 \mathrm{G}^{* *}$ basis set. It is well known in the quantum chemical literature that the B3LYP functional yields a good description of harmonic vibrational wavenumbers for small and medium sized molecules. The optimized structural parameters were used in the vibrational frequency calculations at the DFT levels to characterize all stationary points as minima. The Cartesian representation of the theoretical force constants has been computed at the fully optimized geometry by assuming $C_{s}$ point group symmetry, respectively, for OAA and AA. The theoretical DFT force field was transformed from Cartesian coordinates into the local coordinates and then scaled empirically according to the SQM procedure [5]

$$
F_{i j}^{\text {Scaled }}=\left(C_{i} C_{j}\right)^{1 / 2} F_{i j}^{\text {B3LYP }}
$$

where $C_{i}$ is the scale factor of coordinate $i, F_{i j}^{\text {B3LYP }}$ is the B3LYP/6-31G ${ }^{* *}$ force constant in local coordinate, and $F_{i j}^{\text {Scaled }}$ is the scaled force constant.

The prediction of Raman intensities was carried out by following the procedure outlined below. The Raman activities $\left(S_{i}\right)$ calculated by the Gaussian 03 program and adjusted during the scaling procedure with the MOLVIB program were converted to relative Raman intensities $\left(I_{i}\right)$ using the following relationship derived from the basic theory of Raman scattering [15-17]:

$$
I_{i}=\frac{f\left(v_{o}-v_{i}\right)^{4} S_{i}}{v_{i}\left[1-\exp \left(-h c v_{i} / K T\right)\right]},
$$

where $v_{0}$ is the exciting frequency (in $\mathrm{cm}^{-1}$ units); $v_{i}$ the vibrational wavenumber of the $i$ th normal mode; $h, c$, and $k$ are the fundamental constants, and $f$ is the suitably chosen common normalization factor for all the peak intensities.

The calculated quantum chemical parameters such as the highest occupied molecular orbital energy $\left(E_{\mathrm{HOMO}}\right)$, the lowest unoccupied molecular orbital energy $\left(E_{\mathrm{LUMO}}\right)$, energy gap $(\Delta E)$, chemical potential $\left(P_{i}\right)$, global hardness $(\eta)$, and the softness $(\sigma)$ were calculated. The concept of these parameters is related to each other [18-21], where

$$
\begin{gathered}
P_{i}=-\chi, \\
P_{i}=\frac{\left(E_{\mathrm{HOMO}}+E_{\mathrm{LUMO}}\right)}{2}, \\
\eta=\frac{\left(E_{\mathrm{LUMO}}-E_{\mathrm{HOMO}}\right)}{2} .
\end{gathered}
$$

The inverse values of the global hardness are designated as the softness $\sigma$, as follows:

$$
\sigma=\frac{1}{\eta}
$$

For NMR calculations, the title molecules are firstly optimized and after optimization, ${ }^{1} \mathrm{H}$ and ${ }^{13} \mathrm{C}$ NMR chemical shifts ( $\mathrm{H}$ and $\mathrm{C}$ ) were calculated using the GIAO method in $\mathrm{CDCl}_{3}$ at B3LYP method with $6-31 \mathrm{G}^{* *}$ basis set $[22,23]$. Absolute isotropic magnetic shielding was transformed into chemical shifts by referring to the shielding of a standard compound (TMS) computed at the same level. It has been shown that B3LYP applications were successful in shielding calculations on carbon and hydrogen atoms [23].

\section{Results and Discussion}

4.1. Molecular Geometry. The molecular structures of OAA and AA with $C_{s}$ symmetry are shown in Figures 1(a) and (b), respectively. The optimized bond lengths and angles for OAA and AA using DFT methods are given in Table 1. The global minimum energies obtained by the DFT structure optimization for OAA and AA are calculated as -535.3530 and -535.3627 Hartrees, respectively. The substitution of $\mathrm{OCH}_{3}$ with $\mathrm{COOH}$ group in the OAA and AA leads to strong intermolecular hydrogen bonding and $+\mathrm{I}$ effect, respectively.

4.2. Vibrational Force Constants. Quantum mechanical calculations contain the force constant matrix in Cartesian coordinates and in Hartree/Bohr ${ }^{2}$ units. These force constants were transformed to the force fields in internal local-symmetry coordinates. The local-symmetry coordinates defined in terms of the internal valence coordinates 


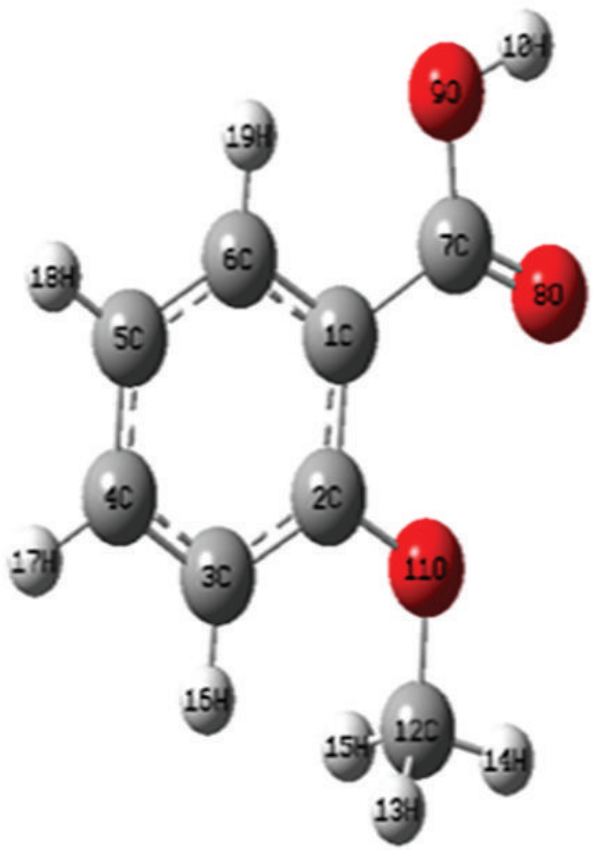

(a)

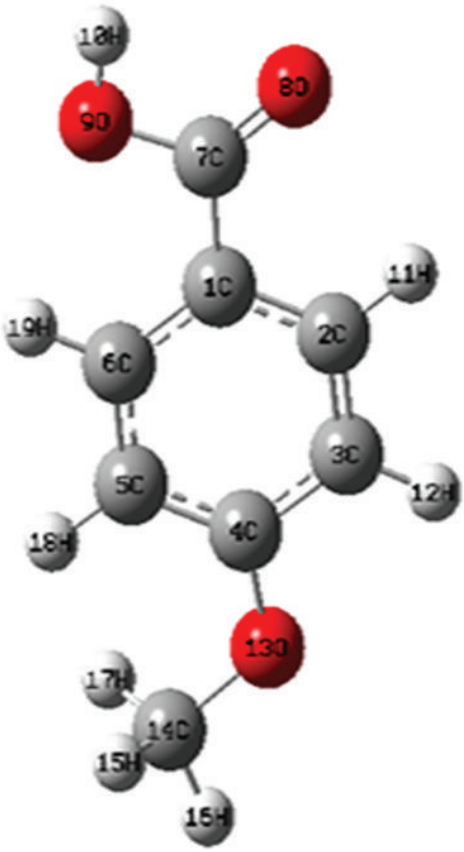

(b)

Figure 1: (a) Molecular structure of O-Anisic acid along with numbering of atoms. (b) Molecular structure of Anisic acid along with numbering of atoms.

TABLE 1: Optimized geometrical parameters O-Anisic acid (OAA) and Anisic acid (AA) obtained by B3LYP/6-31G** density functional calculations.

\begin{tabular}{|c|c|c|c|c|c|}
\hline \multirow{2}{*}{ Bond length $^{\mathrm{a}}$} & \multicolumn{2}{|c|}{ Value $(\AA ̊)$} & \multirow{2}{*}{ Bond angle $^{a}$} & \multicolumn{2}{|c|}{ Value $\left({ }^{\circ}\right)$} \\
\hline & OAA & $\mathrm{AA}$ & & OAA & AA \\
\hline $\mathrm{C} 1-\mathrm{C} 2$ & 1.39 & 1.39 & $\mathrm{C} 1-\mathrm{C} 2-\mathrm{C} 3$ & 119.99 & 119.99 \\
\hline $\mathrm{C} 2-\mathrm{C} 3$ & 1.39 & 1.39 & $\mathrm{C} 2-\mathrm{C} 3-\mathrm{C} 4$ & 119.99 & 119.99 \\
\hline $\mathrm{C} 3-\mathrm{C} 4$ & 1.39 & 1.39 & $\mathrm{C} 3-\mathrm{C} 4-\mathrm{C} 5$ & 120.00 & 120.00 \\
\hline $\mathrm{C} 4-\mathrm{C} 5$ & 1.39 & 1.39 & $\mathrm{C} 4-\mathrm{C} 5-\mathrm{C} 6$ & 119.99 & 119.99 \\
\hline C5-C6 & 1.39 & 1.39 & $\mathrm{C} 2-\mathrm{C} 1-\mathrm{C} 7$ & 120.01 & 120.01 \\
\hline $\mathrm{C} 1-\mathrm{C} 7$ & 1.54 & 1.54 & $\mathrm{C} 1-\mathrm{C} 7-\mathrm{O} 8$ & 130.07 & 130.07 \\
\hline $\mathrm{C} 7-\mathrm{O} 8$ & 1.23 & 1.23 & C1-C7-O9 & 112.29 & 112.29 \\
\hline O9-C7 & 1.35 & 1.35 & C7-O9-H10 & 110.60 & 110.60 \\
\hline O9-H10 & 0.97 & 0.94 & C3-C2-O11(H11) & 119.98 & 119.98 \\
\hline C2-O11(H11) & 1.43 & 1.09 & $\mathrm{C} 2-\mathrm{O} 11-\mathrm{C} 12(\mathrm{C} 4-\mathrm{C} 3-\mathrm{H} 12)$ & 109.50 & 120.01 \\
\hline $\mathrm{C} 11-\mathrm{C} 12(\mathrm{H} 12-\mathrm{C} 2)$ & 1.43 & 1.00 & O11-C12-H13 (C5-C4-O13) & 109.47 & 119.98 \\
\hline $\mathrm{C} 12-\mathrm{H} 13$ (O13-C3) & 1.07 & 1.43 & O11-C12-H14 (C4-O13-C14) & 109.47 & 109.50 \\
\hline C12-H14 (C14-O13) & 1.07 & 1.43 & $\mathrm{O} 11(\mathrm{O} 13)-\mathrm{C} 12(\mathrm{C} 14)-\mathrm{H} 15$ & 109.47 & 109.47 \\
\hline $\mathrm{C} 12(\mathrm{C} 14)-\mathrm{H} 15$ & 1.07 & 1.07 & $\mathrm{C} 4(\mathrm{O} 13)-\mathrm{C} 3(\mathrm{C} 14)-\mathrm{H} 16$ & 120.01 & 109.47 \\
\hline $\mathrm{C} 3(\mathrm{C} 14)-\mathrm{H} 16$ & 1.09 & 1.07 & $\mathrm{C} 5(\mathrm{O} 13)-\mathrm{C} 4(\mathrm{C} 14)-\mathrm{H} 17$ & 119.98 & 109.47 \\
\hline $\mathrm{C} 4(\mathrm{C} 14)-\mathrm{H} 17$ & 1.09 & 1.07 & C6-C5-H18 & 120.00 & 120.00 \\
\hline $\mathrm{C} 5-\mathrm{H} 18$ & 1.09 & 1.09 & C1-C6-H19 & 119.99 & 119.99 \\
\hline C6-H19 & 1.09 & 1.09 & & & \\
\hline
\end{tabular}

${ }^{\mathrm{a}}$ The atoms indicated in the parenthesis belongs to AA.

For numbering of atoms refer to Figures 1(a) and 1(b).

following the IUPAC recommendations $[24,25]$ are given in Tables 4 and 5 for the title compounds.

The bonding properties of OAA and AA are influenced by their rearrangements of electrons during substitutions and addition reactions. The stretching force constants of $\mathrm{C} 1-\mathrm{C} 7$ in OAA and AA are found to be lower than the values of stretching force constant of other $\mathrm{C}-\mathrm{C}$ atoms. The force constant of $\mathrm{C} 1-\mathrm{C} 7$ in OAA is found to be greater than AA due to steric effect (i.e., bulky groups in OAA). The most important diagonal force constants (stretching only) of OAA and AA are listed in Table 6.

4.3. Assignment of Fundamentals. The molecules OAA and AA are disubstituted aromatic system. The vibrational bands 
TABLE 2: Definition of internal coordinates of O-Anisic acid (OAA).

\begin{tabular}{|c|c|c|c|}
\hline No. (i) & Symbol & Type & Definition \\
\hline \multicolumn{4}{|l|}{ Stretching } \\
\hline $1-4$ & $r_{i}$ & $\mathrm{C}-\mathrm{H}$ & C3-H16, C4-H17, C5-H18, C6-H19 \\
\hline $5-11$ & $r_{i}$ & $\mathrm{C}-\mathrm{C}$ & $\mathrm{C} 1-\mathrm{C} 2, \mathrm{C} 2-\mathrm{C} 3, \mathrm{C} 3-\mathrm{C} 4, \mathrm{C} 4-\mathrm{C} 5, \mathrm{C} 5-\mathrm{C} 6, \mathrm{C} 6-\mathrm{C} 1, \mathrm{C} 1-\mathrm{C} 7$ \\
\hline $12-14$ & $r_{i}$ & $\mathrm{C}-\mathrm{O}$ & $\mathrm{C} 7-\mathrm{O} 8, \mathrm{C} 7-\mathrm{O} 9, \mathrm{C} 2-\mathrm{O} 11$ \\
\hline 15 & $r_{i}$ & $\mathrm{O}-\mathrm{C}$ & $\mathrm{O} 11-\mathrm{C} 12$ \\
\hline 16 & $r_{i}$ & $\mathrm{O}-\mathrm{H}$ & O9-H10 \\
\hline $17-19$ & $r_{i}$ & $\mathrm{C}-\mathrm{H}$ (methyl) & $\mathrm{C} 12-\mathrm{H} 13, \mathrm{C} 12-\mathrm{H} 14, \mathrm{C} 12-\mathrm{H} 15$ \\
\hline \multicolumn{4}{|l|}{ Bending } \\
\hline $20-21$ & $\beta_{i}$ & $\mathrm{C}-\mathrm{C}-\mathrm{C}$ & $\mathrm{C} 2-\mathrm{C} 1-\mathrm{C} 7, \mathrm{C} 6-\mathrm{C} 1-\mathrm{C} 7$ \\
\hline $22-29$ & $\beta_{i}$ & $\mathrm{C}-\mathrm{C}-\mathrm{H}$ & $\begin{array}{l}\mathrm{C} 2-\mathrm{C} 3-\mathrm{H} 16, \mathrm{C} 4-\mathrm{C} 3-\mathrm{H} 16, \mathrm{C} 3-\mathrm{C} 4-\mathrm{H} 17, \mathrm{C} 5-\mathrm{C} 4-\mathrm{H} 17 \\
\mathrm{C} 4-\mathrm{C} 5-\mathrm{H} 18, \mathrm{C} 6-\mathrm{C} 5-\mathrm{H} 18, \mathrm{C} 5-\mathrm{C} 6-\mathrm{H} 19, \mathrm{C} 1-\mathrm{C} 6-\mathrm{H} 19\end{array}$ \\
\hline $30-32$ & $\beta_{i}$ & $\mathrm{C}-\mathrm{C}-\mathrm{H}$ (methyl) & O11-C12-H13, O11-C12-H14, O11-C12-H15 \\
\hline $33-35$ & $\beta_{i}$ & $\mathrm{H}-\mathrm{C}-\mathrm{H}$ & H13-C12-H14, H13-C12-H15, H14-C12-H15 \\
\hline $36-37$ & $\beta_{i}$ & $\mathrm{C}-\mathrm{C}-\mathrm{O}$ & $\mathrm{C} 1-\mathrm{C} 7-\mathrm{O} 8, \mathrm{C} 1-\mathrm{C} 7-\mathrm{O} 9$ \\
\hline 38 & $\beta_{i}$ & $\mathrm{C}-\mathrm{O}-\mathrm{H}$ & C7-O9-H10 \\
\hline $39-40$ & $\beta_{i}$ & $\mathrm{C}-\mathrm{C}-\mathrm{O}$ & $\mathrm{C} 1-\mathrm{C} 2-\mathrm{O} 11, \mathrm{C} 3-\mathrm{C} 2-\mathrm{O} 11$ \\
\hline 41 & $\beta_{i}$ & $\mathrm{C}-\mathrm{O}-\mathrm{C}$ & $\mathrm{C} 2-\mathrm{O} 11-\mathrm{C} 12$ \\
\hline $42-47$ & $\beta_{i}$ & C-C-C (Ring) & $\begin{array}{l}\mathrm{C} 1-\mathrm{C} 2-\mathrm{C} 3, \mathrm{C} 2-\mathrm{C} 3-\mathrm{C} 4, \mathrm{C} 3-\mathrm{C} 4-\mathrm{C} 5, \mathrm{C} 4-\mathrm{C} 5-\mathrm{C} 6 \\
\mathrm{C} 5-\mathrm{C} 6-\mathrm{C} 1, \mathrm{C} 6-\mathrm{C} 1-\mathrm{C} 2\end{array}$ \\
\hline \multicolumn{4}{|c|}{ Out-of-plane bending } \\
\hline $48-51$ & $\omega_{i}$ & $\mathrm{C}-\mathrm{H}$ & $\begin{array}{l}\mathrm{H} 16-\mathrm{C} 3-\mathrm{C} 2-\mathrm{C} 4, \mathrm{H} 17-\mathrm{C} 4-\mathrm{C} 5-\mathrm{C} 3, \mathrm{H} 18-\mathrm{C} 5-\mathrm{C} 6-\mathrm{C} 4 \\
\mathrm{H} 19-\mathrm{C} 6-\mathrm{C} 1-\mathrm{C} 5\end{array}$ \\
\hline 52 & $\omega_{i}$ & $\mathrm{C}-\mathrm{C}$ & $\mathrm{C} 7-\mathrm{C} 1-\mathrm{C} 6-\mathrm{C} 2$ \\
\hline 53 & $\omega_{i}$ & $\mathrm{C}-\mathrm{O}$ & $\mathrm{O} 11-\mathrm{C} 2-\mathrm{C} 1-\mathrm{C} 3$ \\
\hline \multicolumn{4}{|l|}{ Torsion } \\
\hline $54-55$ & $\tau_{i}$ & $\mathrm{C}-\mathrm{O}$ & $\mathrm{C} 2-\mathrm{C} 1-\mathrm{C} 7-\mathrm{O} 8, \mathrm{C} 2-\mathrm{C} 1-\mathrm{C} 7-\mathrm{O} 9$ \\
\hline $56-57$ & $\tau_{i}$ & $\mathrm{C}-\mathrm{O}-\mathrm{C}$ & $\mathrm{C} 1-\mathrm{C} 2-\mathrm{O} 11-\mathrm{C} 12, \mathrm{C} 3-\mathrm{C} 2-\mathrm{O} 11-\mathrm{C} 12$ \\
\hline $58-60$ & $\tau_{i}$ & C-H(methyl) & $\begin{array}{l}\text { C2-O11-C12-H13, C2-O11-C12-H14, } \\
\text { C2-O11-C12-H15 }\end{array}$ \\
\hline 61 & $\tau_{i}$ & $\mathrm{O}-\mathrm{H}$ & C1-C7-O9-H10 \\
\hline $62-67$ & $\tau_{i}$ & tring & $\begin{array}{l}\mathrm{C} 1-\mathrm{C} 2-\mathrm{C} 3-\mathrm{C} 4, \mathrm{C} 2-\mathrm{C} 3-\mathrm{C} 4-\mathrm{C} 5, \mathrm{C} 3-\mathrm{C} 4-\mathrm{C} 5-\mathrm{C} 6 \\
\mathrm{C} 4-\mathrm{C} 5-\mathrm{C} 6-\mathrm{C} 1, \mathrm{C} 5-\mathrm{C} 6-\mathrm{C} 1-\mathrm{C} 2, \mathrm{C} 6-\mathrm{C} 1-\mathrm{C} 2-\mathrm{C} 3\end{array}$ \\
\hline
\end{tabular}

For numbering of atoms refer to Figure 1(a).

observed in the IR region are very sharp, broad, and less intense. The title compounds belong to $C_{s}$ point group. The 19 atoms present in OAA and AA molecular structure, each has 51 fundamental modes of vibrations. For molecules of $C_{s}$ symmetry, group theory analysis indicates that the 51 fundamental vibrations are distributed among the symmetry species as

$$
\left.\Gamma_{\text {vib }}=35 \mathrm{~A}^{\prime} \text { (in-plane }\right)+16 \mathrm{~A}^{\prime \prime} \text { (out-of-plane) }
$$

for both OAA and AA, respectively. From the structural point of view of the molecules, OAA and AA have 18 stretching vibrations 33 bending vibrations, respectively. All the vibrations were found to be active both in Raman scattering and infrared absorption.

The observed and calculated wave numbers, calculated IR and Raman intensities, and normal mode descriptions (characterized by potential energy distribution (PED)) for the fundamental vibrations of OAA and AA are depicted in Tables 7 and 8. For visual comparison, the observed and simulated FTIR and FT-Raman spectra of the compounds are presented in Figures 2, 3, 4, and 5, which help to understand the observed spectral features. The root mean square (RMS) error of the observed and calculated wavenumbers (unscaled/B3LYP/6-31G ${ }^{* *}$ ) of OAA and AA was found to be $84.3 \mathrm{~cm}^{-1}$ and $89.1 \mathrm{~cm}^{-1}$, respectively. This is understandable since the mechanical force fields usually differ appreciably from the observed ones. This is partly due to the neglect of anharmonicity and partly due to the approximate nature of the quantum mechanical methods. However for reliable information on the vibrational properties, the use of selective scaling is necessary. The calculated wavenumbers are scaled using the set of transferable scale factors recommended by Fogarasi and Pulay [7]. The SQM treatment has resulted in an RMS deviation of $9.67 \mathrm{~cm}^{-1}$ and $11.3 \mathrm{~cm}^{-1}$ for OAA and AA, 
TABLE 3: Definition of internal coordinates of Anisic acid (AA).

\begin{tabular}{|c|c|c|c|}
\hline No. (i) & Symbol & Type & Definition \\
\hline \multicolumn{4}{|l|}{ Stretching } \\
\hline $1-4$ & $r_{i}$ & $\mathrm{C}-\mathrm{H}$ & C2-H11, C3-H12, C5-H18, C6-H19 \\
\hline $5-10$ & $r_{i}$ & $\mathrm{C}-\mathrm{C}$ & $\mathrm{C} 1-\mathrm{C} 2, \mathrm{C} 2-\mathrm{C} 3, \mathrm{C} 3-\mathrm{C} 4, \mathrm{C} 4-\mathrm{C} 5, \mathrm{C} 5-\mathrm{C} 6, \mathrm{C} 6-\mathrm{C} 1$ \\
\hline 11 & $r_{i}$ & $\mathrm{C}-\mathrm{Cfn}$ & $\mathrm{C} 1-\mathrm{C} 7$ \\
\hline $12-14$ & $r_{i}$ & $\mathrm{C}-\mathrm{O}$ & $\mathrm{C} 7-\mathrm{O} 8, \mathrm{C} 7-\mathrm{O} 9, \mathrm{C} 4-\mathrm{O} 13$ \\
\hline 15 & $r_{i}$ & $\mathrm{O}-\mathrm{C}$ & $\mathrm{O} 13-\mathrm{Cl} 4$ \\
\hline 16 & $r_{i}$ & $\mathrm{O}-\mathrm{H}$ & O9-H10 \\
\hline $17-19$ & $r_{i}$ & C-H(methyl) & C14-H15, C14-H16, C14-H17 \\
\hline \multicolumn{4}{|l|}{ Bending } \\
\hline $20-21$ & $\beta_{i}$ & $\mathrm{C}-\mathrm{C}$ & $\mathrm{C} 2-\mathrm{C} 1-\mathrm{C} 7, \mathrm{C} 6-\mathrm{C} 1-\mathrm{C} 7$ \\
\hline $22-29$ & $\beta_{i}$ & $\mathrm{C}-\mathrm{C}-\mathrm{H}$ & $\begin{array}{l}\text { C1-C2-H11, C3-C2-H11, } \\
\text { C2-C3-H12, C4-C3-H12, } \\
\text { C4-C5-H18, C6-C5-H18, } \\
\text { C5-C6-H19, C1-C6-H19 }\end{array}$ \\
\hline $30-35$ & $\beta_{i}$ & $\mathrm{C}-\mathrm{C}-\mathrm{H}$ (methyl) & $\begin{array}{l}\text { O13-C14-H15, O13-C14-H16, O13-C14-H17, } \\
\text { H17-C14-H15, H15-C14-H16, H17-C14-H16 }\end{array}$ \\
\hline $36-37$ & $\beta_{i}$ & $\mathrm{C}-\mathrm{C}-\mathrm{O}$ & $\mathrm{C} 3-\mathrm{C} 4-\mathrm{O} 13, \mathrm{C} 5-\mathrm{C} 4-\mathrm{O} 13$ \\
\hline 38 & $\beta_{i}$ & $\mathrm{C}-\mathrm{O}-\mathrm{H}$ & C7-O9-H10 \\
\hline $39-40$ & $\beta_{i}$ & $\mathrm{C}-\mathrm{C}-\mathrm{O}$ & $\mathrm{C} 1-\mathrm{C} 7-\mathrm{O} 8, \mathrm{C} 1-\mathrm{C} 7-\mathrm{O} 9$ \\
\hline 41 & $\beta_{i}$ & $\mathrm{C}-\mathrm{O}-\mathrm{C}$ & $\mathrm{C} 4-\mathrm{O} 13-\mathrm{C} 14$ \\
\hline $42-47$ & $\beta_{i}$ & $\mathrm{C}-\mathrm{C}-\mathrm{C}$ (Ring) & $\begin{array}{l}\mathrm{C} 1-\mathrm{C} 2-\mathrm{C} 3, \mathrm{C} 2-\mathrm{C} 3-\mathrm{C} 4, \mathrm{C} 3-\mathrm{C} 4-\mathrm{C} 5, \mathrm{C} 4-\mathrm{C} 5-\mathrm{C} 6 \\
\mathrm{C} 5-\mathrm{C} 6-\mathrm{C} 1, \mathrm{C} 6-\mathrm{C} 1-\mathrm{C} 2\end{array}$ \\
\hline \multicolumn{4}{|c|}{ Out-of-plane bending } \\
\hline $48-51$ & $\omega_{i}$ & $\mathrm{C}-\mathrm{H}$ & $\begin{array}{l}\mathrm{H} 11-\mathrm{C} 2-\mathrm{C} 3-\mathrm{C} 1, \mathrm{H} 12-\mathrm{C} 3-\mathrm{C} 4-\mathrm{C} 2, \mathrm{H} 18-\mathrm{C} 5-\mathrm{C} 6-\mathrm{C} 4, \\
\mathrm{H} 19-\mathrm{C} 6-\mathrm{C} 1-\mathrm{C} 5\end{array}$ \\
\hline 52 & $\omega_{i}$ & $\mathrm{C}-\mathrm{C}$ & $\mathrm{C} 7-\mathrm{C} 1-\mathrm{C} 6-\mathrm{C} 2$ \\
\hline 53 & $\omega_{i}$ & $\mathrm{C}-\mathrm{O}$ & $\mathrm{O} 13-\mathrm{C} 4-\mathrm{C} 5-\mathrm{C} 3$ \\
\hline \multicolumn{4}{|l|}{ Torsion } \\
\hline $54-55$ & $\tau_{i}$ & $\mathrm{C}-\mathrm{O}$ & $\mathrm{C} 2-\mathrm{C} 1-\mathrm{C} 7-\mathrm{O} 8, \mathrm{C} 2-\mathrm{C} 1-\mathrm{C} 7-\mathrm{O} 9$ \\
\hline $56-57$ & $\tau_{i}$ & $\mathrm{C}-\mathrm{O}-\mathrm{C}$ & C3-C4-O13-C14, C5-C4-O13-C14 \\
\hline $58-60$ & $\tau_{i}$ & C-H(methyl) & $\begin{array}{l}\text { C4-O13-C14-H15, C4-O13-C14-H16, } \\
\text { C4-O13-C14-H16 }\end{array}$ \\
\hline 61 & $\tau_{i}$ & $\mathrm{O}-\mathrm{H}$ & $\mathrm{C} 1-\mathrm{C} 7-\mathrm{O} 9-\mathrm{H} 10$ \\
\hline $62-67$ & $\tau_{i}$ & tring & $\begin{array}{l}\mathrm{C} 1-\mathrm{C} 2-\mathrm{C} 3-\mathrm{C} 4, \mathrm{C} 2-\mathrm{C} 3-\mathrm{C} 4-\mathrm{C} 5, \mathrm{C} 3-\mathrm{C} 4-\mathrm{C} 5-\mathrm{C} 6 \\
\mathrm{C} 4-\mathrm{C} 5-\mathrm{C} 6-\mathrm{C} 1, \mathrm{C} 5-\mathrm{C} 6-\mathrm{C} 1-\mathrm{C} 2, \mathrm{C} 6-\mathrm{C} 1-\mathrm{C} 2-\mathrm{C} 3\end{array}$ \\
\hline
\end{tabular}

For numbering of atoms refer to Figure 1(b).

respectively. The RMS values of wavenumbers were obtained in this study using the following expression

$$
\mathrm{RMS}=\sqrt{\frac{1}{n-1} \sum_{i}^{n}\left(v_{i}^{\mathrm{calc}}-v_{i}^{\exp }\right)^{2}}
$$

4.3.1. CH Vibrations. Aromatic compounds commonly exhibit multiple weak bands in the region $3100-3000 \mathrm{~cm}^{-1}$ [26] due to aromatic $\mathrm{C}-\mathrm{H}$ stretching vibrations. According to the PED analysis, the bands observed in experimental spectrum at $3098,3083,3069,3020 \mathrm{~cm}^{-1}$ in OAA and $3085,3034,3029$, and $3002 \mathrm{~cm}^{-1}$ in AA were assigned to stretching vibrations of
$\mathrm{C}-\mathrm{H}$ bond. According to these studies, all the $\mathrm{C}-\mathrm{H}$ stretching vibrations are not mixed with other types of vibrations.

The $\mathrm{C}-\mathrm{H}$ in-plane deformation vibrations are assigned in the region $1100-1400 \mathrm{~cm}^{-1}$ [27]. The in-plane deformations of $\mathrm{C}-\mathrm{H}$ groups are noticed on PED analysis at 1494, 1439, 1288, and 1182 in OAA and 1518, 1301, 1181 and $1131 \mathrm{~cm}^{-1}$ in AA. There is slight increase in the $\mathrm{C}-\mathrm{H}$ in-plane deformation frequency because of steric effect in OAA and inductive effect $(+\mathrm{I})$ in AA. These values of calculated frequencies are typical and in very good agreement with experimental data. The inplane $\mathrm{C}-\mathrm{H}$ deformation vibrations are slightly mixed in both $\mathrm{OAA}$ and $\mathrm{AA}$.

The $\mathrm{C}-\mathrm{H}$ out-of-plane deformation vibrations are assigned in the region $900-600 \mathrm{~cm}^{-1}$ [26]. The bands 
TABLE 4: Definition of natural internal coordinates of O-Anisic acid (OAA).

\begin{tabular}{|c|c|c|}
\hline No. (i) & Symbol $^{\mathrm{a}}$ & Definition $^{\mathrm{b}}$ \\
\hline $1-4$ & C-H stretch & $r_{1}, r_{2}, r_{3}, r_{4}$ \\
\hline $5-11$ & $\mathrm{C}-\mathrm{C}$ stretch & $r_{5}, r_{6}, r_{7}, r_{8}, r_{9}, r_{10}, r_{11}$ \\
\hline $12-14$ & $\mathrm{C}-\mathrm{O}$ stretch & $r_{12}, r_{13}, r_{14}$ \\
\hline 15 & $\mathrm{O}-\mathrm{C}$ stretch & $r_{15}$ \\
\hline 16 & $\mathrm{O}-\mathrm{H}$ stretch & $r_{16}$ \\
\hline 17 & $\mathrm{CH}_{3}$ ss & $\left(r_{17}+r_{18}+r_{19}\right) / \sqrt{ } 3$ \\
\hline 18 & $\mathrm{CH}_{3}$ ips & $\left(2 r_{17}-r_{18}-r_{19}\right) / \sqrt{ } 6$ \\
\hline 19 & $\mathrm{CH}_{3}$ ops & $\left(r_{18}-r_{19}\right) / \sqrt{ } 2$ \\
\hline 20 & $\mathrm{bC}-\mathrm{C}-\mathrm{C}$ & $\left(\beta_{20}-\beta_{21}\right) / \sqrt{ } 2$ \\
\hline $21-24$ & $\mathrm{bC}-\mathrm{C}-\mathrm{H}$ & $\left(\beta_{22}-\beta_{23}\right) / \sqrt{ } 2,\left(\beta_{24}-\beta_{25}\right) / \sqrt{ } 2,\left(\beta_{26}-\beta_{27}\right) / \sqrt{ } 2,\left(\beta_{28}-\beta_{29}\right) / \sqrt{ } 2$ \\
\hline 25 & $\mathrm{CH}_{3} \mathrm{sb}$ & $\left(-\beta_{30}-\beta_{31}-\beta_{32}+\beta_{33}+\beta_{34}+\beta_{35}\right) / \sqrt{ } 6$ \\
\hline 26 & $\mathrm{CH}_{3} \mathrm{ipb}$ & $\left(-\beta_{33}-\beta_{34}-2 \beta_{35}\right) / \sqrt{ } 6$ \\
\hline 27 & $\mathrm{CH}_{3} \mathrm{opb}$ & $\left(\beta_{33}-\beta_{34}\right) / \sqrt{ } 2$ \\
\hline 28 & $\mathrm{CH}_{3}$ ipr & $\left(2 \beta_{30}-\beta_{31}-\beta_{32}\right) / \sqrt{ } 6$ \\
\hline 29 & $\mathrm{CH}_{3}$ opr & $\left(\beta_{31}-\beta_{32}\right) / \sqrt{ } 2$ \\
\hline 30 & $\mathrm{bC}-\mathrm{C}-\mathrm{O}$ & $\left(\beta_{36}-\beta_{37}\right) / \sqrt{ } 2$ \\
\hline 31 & bC-O-H & $\beta_{38}$ \\
\hline $32-33$ & $\mathrm{bC}-\mathrm{C}-\mathrm{O}$ & $\beta_{39}, \beta_{40}$ \\
\hline 34 & $\mathrm{bC}-\mathrm{O}-\mathrm{C}$ & $\beta_{41}$ \\
\hline 35 & Rtrigd & $\left(\beta_{42}-\beta_{43}+\beta_{44}-\beta_{45}+\beta_{46}-\beta_{47}\right) / \sqrt{ } 6$ \\
\hline 36 & Rsymd & $\left(-\beta_{42}-\beta_{43}+\beta_{44}-\beta_{45}-\beta_{46}+2 \beta_{47}\right) / \sqrt{ } 12$ \\
\hline 37 & Rasymd & $\left(\beta_{42}-\beta_{43}+\beta_{45}-\beta_{46}\right) / 2$ \\
\hline $38-41$ & $\omega \mathrm{C}-\mathrm{H}$ & $\omega_{48}, \omega_{49}, \omega_{50}, \omega_{51}$ \\
\hline 42 & $\omega \mathrm{C}-\mathrm{C}$ & $\omega_{52}$ \\
\hline 43 & $\omega \mathrm{C}-\mathrm{O}$ & $\omega_{53}$ \\
\hline $44-45$ & $\mathrm{tC}-\mathrm{O}$ & $\tau_{54}, \tau_{55}$ \\
\hline 46 & $\mathrm{tC}-\mathrm{O}-\mathrm{C}$ & $1 / 2\left(\tau_{56}+\tau_{57}\right)$ \\
\hline 47 & $\mathrm{tCH}_{3}$ & $1 / 3\left(\tau_{58}+\tau_{59}+\tau_{60}\right)$ \\
\hline 48 & $\mathrm{tO}-\mathrm{H}$ & $\tau_{61}$ \\
\hline 49 & Ttrigd & $\left(\tau_{62}-\tau_{63}+\tau_{64}-\tau_{65}+\tau_{66}-\tau_{67}\right) / \sqrt{ } 6$ \\
\hline 50 & Tsymd & $\left(\tau_{62}-\tau_{63}+\tau_{65}+\tau_{66}\right) / 2$ \\
\hline 51 & Tasymd & $\left(-\tau_{62}+2 \tau_{63}-\tau_{64}-\tau_{65}+\tau_{66}-\tau_{67}\right) / \sqrt{ } 12$ \\
\hline
\end{tabular}

${ }^{\mathrm{a}}$ These symbols are used for description of the normal modes by PED in Table 7.

${ }^{\mathrm{b}}$ The internal coordinates used here are defined in Table 2.

appearing at $960,937,865$, and $755 \mathrm{~cm}^{-1}$ in OAA and $929,854,846$, and $774 \mathrm{~cm}^{-1}$ in AA were assigned to out-of-plane deformation type of vibration $(\omega)$ of $\mathrm{C}-\mathrm{H}$ groups. There is slight increase in the $\mathrm{C}-\mathrm{H}$ out-of-plane deformation frequency because of strong intermolecular hydrogen bonding in OAA. In these bands, the pronounced participation of other types of vibrations is observed. These are also supported by the literature.

4.3.2. Carboxylic Acid Vibrations. Due to the presence of strong intermolecular hydrogen bonding, the FT-IR spectra exhibits spectra exhibit a broad band due to the $\mathrm{O}-\mathrm{H}$ stretching vibrations and a strong band due to $\mathrm{C}=\mathrm{O}$ stretching vibrations. The carboxylic acid dimers display a very broad and intense $\mathrm{O}-\mathrm{H}$ stretching absorption in the region of 3300$2500 \mathrm{~cm}^{-1}$ [28]. The title molecules both exhibit intermolecular hydrogen bonding. In our case, the bands at $3390 \mathrm{~cm}^{-1}$ in OAA and $3435 \mathrm{~cm}^{-1}$ in AA are assigned as $\mathrm{O}-\mathrm{H}$ stretching vibrations. There is a slight increase in the $\mathrm{O}-\mathrm{H}$ frequency because of steric effect in OAA and $+\mathrm{I}$ effect in AA. The O$\mathrm{H}$ out-of-plane bending vibration occurs near the region of $920 \mathrm{~cm}^{-1}$ [27]. The bands appearing at $595 \mathrm{~cm}^{-1}$ in OAA and $505 \mathrm{~cm}^{-1}$ in AA are assigned to $\mathrm{O}-\mathrm{H}$ out-of-plane bending vibration. The $\mathrm{O}-\mathrm{H}$ out-of-plane bending vibrations in OAA and AA decrease due to intermolecular hydrogen bonding.

The carbonyl stretching vibrations are expected in the region $1720 \mathrm{~cm}^{-1}-1680 \mathrm{~cm}^{-1}$ [28]. The IR band at $1670 \mathrm{~cm}^{-1}$ in OAA and FT-Raman band at $1688 \mathrm{~cm}^{-1}$ in AA are assigned as $\mathrm{C}=\mathrm{O}$ stretching vibrations. The $\mathrm{C}-\mathrm{O}$ bond appears strongly in the $1320-1210 \mathrm{~cm}^{-1}$ region [29]. The bands observed at 1049 , and $795 \mathrm{~cm}^{-1}$ in OAA and 1267 , and $1100 \mathrm{~cm}^{-1}$ in AA are assigned to $\mathrm{C}-\mathrm{O}$ stretching mode. The $\mathrm{C}-\mathrm{O}$ stretching vibrational frequency is lower than general range. In the case of carboxylic acid dimers like OAA and AA, the $\mathrm{OH}$ 
TABLE 5: Definition of natural internal coordinates of Anisic acid (AA).

\begin{tabular}{|c|c|c|}
\hline No. (i) & Symbol $^{\mathrm{a}}$ & Definition $^{\mathrm{b}}$ \\
\hline $1-4$ & C-H stretch & $r_{1}, r_{2}, r_{3}, r_{4}$ \\
\hline $5-10$ & C-C stretch & $r_{5}, r_{6}, r_{7}, r_{8}, r_{9}, r_{10}$ \\
\hline 11 & C-Cfn stretch & $r_{11}$ \\
\hline $12-14$ & $\mathrm{C}-\mathrm{O}$ stretch & $r_{12}, r_{13}, r_{14}$ \\
\hline 15 & O-C stretch & $r_{15}$ \\
\hline 16 & $\mathrm{O}-\mathrm{H}$ stretch & $r_{16}$ \\
\hline 17 & $\mathrm{CH}_{3}$ ss & $\left(r_{17}+r_{18}+r_{19}\right) / \sqrt{ } 3$ \\
\hline 18 & $\mathrm{CH}_{3}$ ips & $\left(2 r_{17}-r_{18}-r_{19}\right) / \sqrt{ } 6$ \\
\hline 19 & $\mathrm{CH}_{3}$ ops & $\left(r_{18}-r_{19}\right) / \sqrt{ } 2$ \\
\hline 20 & $\mathrm{bC}-\mathrm{C}-\mathrm{C}$ & $\left(\beta_{20}-\beta_{21}\right) / \sqrt{ } 2$ \\
\hline $21-24$ & $\mathrm{bC}-\mathrm{C}-\mathrm{H}$ & $\left(\beta_{22}-\beta_{23}\right) / \sqrt{ } 2,\left(\beta_{24}-\beta_{25}\right) / \sqrt{ } 2,\left(\beta_{26}-\beta_{27}\right) / \sqrt{ } 2,\left(\beta_{28}-\beta_{29}\right) / \sqrt{ } 2$ \\
\hline 25 & $\mathrm{CH}_{3} \mathrm{sb}$ & $\left(-\beta_{30}-\beta_{31}-\beta_{32}+\beta_{33}+\beta_{34}+\beta_{35}\right) / \sqrt{ } 6$ \\
\hline 26 & $\mathrm{CH}_{3}$ ipb & $\left(-\beta_{33}-\beta_{34}-2 \beta_{35}\right) / \sqrt{ } 6$ \\
\hline 27 & $\mathrm{CH}_{3}$ opb & $\left(\beta_{33}-\beta_{34}\right) / \sqrt{ } 2$ \\
\hline 28 & $\mathrm{CH}_{3}$ ipr & $\left(2 \beta_{30}-\beta_{31}-\beta_{32}\right) / \sqrt{ } 6$ \\
\hline 29 & $\mathrm{CH}_{3}$ opr & $\left(\beta_{31}-\beta_{32}\right) / \sqrt{ } 2$ \\
\hline 30 & $\mathrm{bC}-\mathrm{C}-\mathrm{O}$ & $\left(\beta_{35}-\beta_{36}\right) / \sqrt{ } 2$ \\
\hline 31 & $\mathrm{bC}-\mathrm{O}-\mathrm{H}$ & $\beta_{38}$ \\
\hline $32-33$ & $\mathrm{bC}-\mathrm{C}-\mathrm{O}$ & $\beta_{39}, \beta_{40}$ \\
\hline 34 & $\mathrm{bC}-\mathrm{O}-\mathrm{C}$ & $\beta_{41}$ \\
\hline 35 & Rtrigd & $\left(\beta_{42}-\beta_{43}+\beta_{44}-\beta_{45}+\beta_{46}-\beta_{47}\right) / \sqrt{ } 6$ \\
\hline 36 & Rsymd & $\left(-\beta_{42}-\beta_{43}+\beta_{44}-\beta_{45}-\beta_{46}+2 \beta_{47}\right) / \sqrt{ } 12$ \\
\hline 37 & Rasymd & $\left(\beta_{42}-\beta_{43}+\beta_{45}-\beta_{46}\right) / 2$ \\
\hline $38-41$ & $\omega \mathrm{C}-\mathrm{H}$ & $\omega_{48}, \omega_{49}, \omega_{50}, \omega_{51}$ \\
\hline 42 & $\omega \mathrm{C}-\mathrm{C}$ & $\omega_{52}$ \\
\hline 43 & $\omega \mathrm{C}-\mathrm{O}$ & $\omega_{53}$ \\
\hline $44-45$ & $\mathrm{tC}-\mathrm{O}$ & $\tau_{54}, \tau_{55}$ \\
\hline 46 & $\mathrm{tC}-\mathrm{O}-\mathrm{C}$ & $1 / 2\left(\tau_{56}+\tau_{57}\right)$ \\
\hline 47 & $\mathrm{tCH}_{3}$ & $1 / 3\left(\tau_{58}+\tau_{59}+\tau_{60}\right)$ \\
\hline 48 & $\mathrm{tO}-\mathrm{H}$ & $\tau_{61}$ \\
\hline 49 & Ttrigd & $\left(\tau_{62}-\tau_{63}+\tau_{64}-\tau_{65}+\tau_{66}-\tau_{67}\right) / \sqrt{ } 6$ \\
\hline 50 & Tsymd & $\left(\tau_{62}-\tau_{63}+\tau_{65}+\tau_{66}\right) / 2$ \\
\hline 51 & Tasymd & $\left(-\tau_{62}+2 \tau_{63}-\tau_{64}-\tau_{65}+\tau_{66}-\tau_{67}\right) / \sqrt{ } 12$ \\
\hline
\end{tabular}

${ }^{\mathrm{a}}$ These symbols are used for description of the normal modes by PED in Table 8.

${ }^{\mathrm{b}}$ The internal coordinates used here are defined in Table 3.

in-plane bending and $\mathrm{C}-\mathrm{O}$ stretching bands involve some interaction between them, they are referred to as coupled $\mathrm{OH}$ in-plane bending and $\mathrm{C}-\mathrm{O}$ stretching vibrations [26]. The $\mathrm{C}-\mathrm{O}$ bending vibration occurs in the region of $580-$ $340 \mathrm{~cm}^{-1}$ [30]. The band observed at $380 \mathrm{~cm}^{-1}$ in OAA and $440 \mathrm{~cm}^{-1}$ in AA are assigned to $\mathrm{C}-\mathrm{O}$ bending mode. The present assignments agree very well with the values available in the literature.

4.3.3. Methyl Group Vibrations. The title molecules OAA and AA under consideration possess one $\mathrm{CH}_{3}$ group. For the assignments of $\mathrm{CH}_{3}$ group one can expect that 9 fundamentals can be associated with each $\mathrm{CH}_{3}$ group, namely, the symmetrical stretching $\left(\mathrm{CH}_{3}\right.$ symmetric stretch) and asymmetrical stretching $\left(\mathrm{CH}_{3}\right.$ asymmetric stretch), in-plane stretching modes (i.e., in-plane hydrogen stretching modes), and the symmetrical $\left(\mathrm{CH}_{3}\right.$ symmetric deform) and asymmetrical $\left(\mathrm{CH}_{3}\right.$ asymmetric deform) deformation modes; inplane rocking $\left(\mathrm{CH}_{3} \mathrm{ipr}\right)$, out-of-plane rocking $\left(\mathrm{CH}_{3} \mathrm{opr}\right)$, and twisting $\left(\mathrm{tCH}_{3}\right)$ bending modes.

For the methyl group compounds, the asymmetric stretching mode appeared in the range $2965-3005 \mathrm{~cm}^{-1}$, and the symmetric stretching mode appeared in the range of $2815-2860 \mathrm{~cm}^{-1}$ [30]. The FT-Raman band at $2983 \mathrm{~cm}^{-1}$ for OAA, and IR band at $2941 \mathrm{~cm}^{-1}$ for AA are symmetric stretching. The symmetric stretching vibrational frequency is higher in OAA and AA due to steric effect and +I effect. The asymmetric methyl stretching band appeared at 3003, $3018 \mathrm{~cm}^{-1}$ in OAA and 2990, $2956 \mathrm{~cm}^{-1}$ in AA, respectively. The asymmetric deformation mode appeared in the range $1445-1485 \mathrm{~cm}^{-1}$ and symmetric deformation mode appeared in the range of $1420-1460 \mathrm{~cm}^{-1}$ [30]. The IR band at 1466 , 


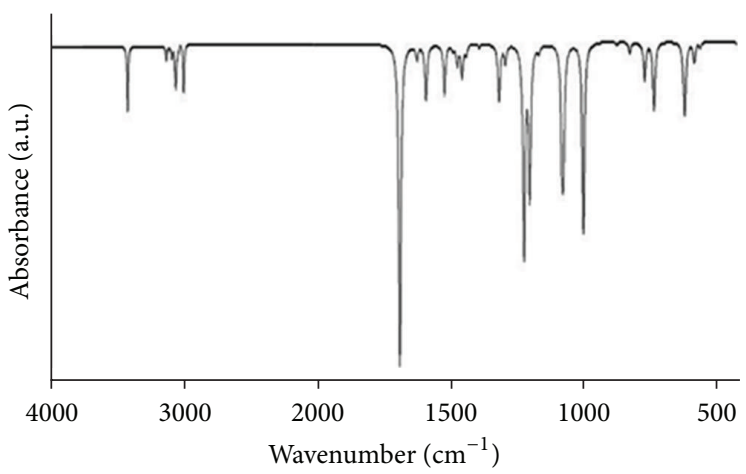

(a)

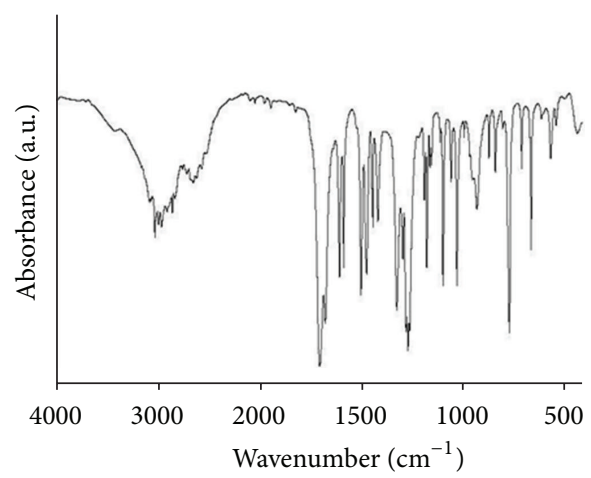

(b)

FIGURE 2: FTIR spectra of O-Anisic acid (a) observed and (b) calculated with B3LYP/6-31G**.

TABLE 6: Diagonal force constants $\left(10^{2} \mathrm{Nm}^{-1}\right)$ of O-Anisic acid (OAA) and Anisic acid (AA).

\begin{tabular}{lcc}
\hline Description $^{\mathrm{a}}$ & \multicolumn{2}{c}{ Force constants $^{\mathrm{b}}$} \\
\hline C1-C2 & OAA & AA \\
C2-C3 & 6.21 & 6.30 \\
C3-C4 & 6.33 & 6.96 \\
C4-C5 & 6.77 & 6.26 \\
C5-C6 & 6.75 & 6.28 \\
C6-C1 & 6.82 & 6.63 \\
C1-C7 & 6.44 & 6.48 \\
C7-O8 & 4.65 & 2.22 \\
C7-O9 & 5.32 & 5.22 \\
C2-O11(C4-O13) & 10.30 & 11.28 \\
O11-C12(O13-C14) & 4.49 & 5.76 \\
O9-H10 & 4.13 & 4.99 \\
C12-H13(C14-H15) & 6.44 & 6.61 \\
C12-H14(C14-H16) & 4.98 & 5.08 \\
C12-H15(C14-H17) & 5.26 & 4.70 \\
C3-H16(C2-H11) & 4.98 & 5.07 \\
C4-H17(C3-H12) & 5.14 & 4.98 \\
C5-H18 & 5.01 & 4.96 \\
C6-H19 & 5.05 & 5.00 \\
\hline
\end{tabular}

${ }^{\mathrm{a}}$ The atoms indicated in the parenthesis belong to AA.

${ }^{\mathrm{b}}$ Stretching force constants are given in mdyn $\AA^{-1}$.

For numbering of atoms refer to Figures $1(a)$ and $1(b)$.

and $1435 \mathrm{~cm}^{-1}$ in OAA and 1468 , and $1461 \mathrm{~cm}^{-1}$ in AA are assigned as asymmetric deformation vibrations. The IR band at $1411 \mathrm{~cm}^{-1}$ for OAA and $1429 \mathrm{~cm}^{-1}$ for AA are symmetric deformation mode. The $\mathrm{CH}_{3}$ deformation absorption occurs at $1466 \mathrm{~cm}^{-1}$ and $1429 \mathrm{~cm}^{-1}$; this vibration is known as umbrella mode that overlaps with $\mathrm{CC}$ ring stretching vibrations for the title compounds. These are also supported by the literature.

The tensional modes appeared in the range of 265$185 \mathrm{~cm}^{-1}$ [30]. This modes are strongly coupled with other vibrations that are observed at $280 \mathrm{~cm}^{-1}$ in OAA and $165 \mathrm{~cm}^{-1}$ in AA which are in agreement with the calculated results also.

4.3.4. Ring Vibrations. The ring $\mathrm{C}-\mathrm{C}$ stretching vibrations occur in the region of $1600-1400 \mathrm{~cm}^{-1}$ [29]. The bands appear at $1600,1579,1312,1184,1153,1062$, and $698 \mathrm{~cm}^{-1}$ in OAA and $1608,1580,1416,1307,1107,1028$, and $825 \mathrm{~cm}^{-1}$ in AA were assigned to $\mathrm{C}-\mathrm{C}$ stretching vibrations. The shift in the frequency of $\mathrm{C}-\mathrm{C}$ vibrations towards lower wave number may be due to the $\mathrm{COOH}$ and $\mathrm{OCH}_{3}$ groups. Many ring modes are affected by the substitutions in the aromatic ring. The bands at $180 \mathrm{~cm}^{-1}$ and $285 \mathrm{~cm}^{-1}$ for OAA and AA were assigned to $\mathrm{C}-\mathrm{C}$ bending vibrations. The out-of-plane and inplane deformations of the phenyl ring are observed below $1000 \mathrm{~cm}^{-1}$, and these modes are sensitive by the addition of functional groups. The out-of-plane bending vibrations were observed at $170 \mathrm{~cm}^{-1}$ and $111 \mathrm{~cm}^{-1}$ for OAA and AA. Small changes in the wavenumbers were observed due to the presence of $+\mathrm{I}$ effect in AA and steric effect in OAA. The computed wavenumbers are in good agreement with experimental data.

\section{Electronic Properties}

Atomic charges on the various atoms of OAA and AA obtained by Mulliken population analysis [31] are given in Table 9. From the listed atomic charge values, the oxygen $[\mathrm{O} 8,09]$ and $\mathrm{O} 11$ in OAA and $\mathrm{O} 13$ in AA atoms had a large negative charge and behaved as electron acceptor. It was also observed that there is a large accumulation of charge on O11 in OAA, $\mathrm{O} 13$ in AA molecules. Therefore, C7 and O11 in OAA and $\mathrm{C} 7$ and $\mathrm{O} 13$ in AA had a greater ionic character.

Natural bond orbital analysis provides an efficient method for studying steric effect and intermolecular bonding and interaction among bonds and also provides a convenient basis for investigating charge transfer or conjugative interaction in molecular systems. Natural charge analysis is given in Table 10 for the title compounds. The results show that substitution of $\mathrm{COOH}$ and $\mathrm{CH}_{3}$ group in OAA and AA leads to a redistribution of electron density. The $\mathrm{C} 7$ atom in OAA and $\mathrm{AA}$ is more positive charge $(+0.8091,+0.8139)$. In the 


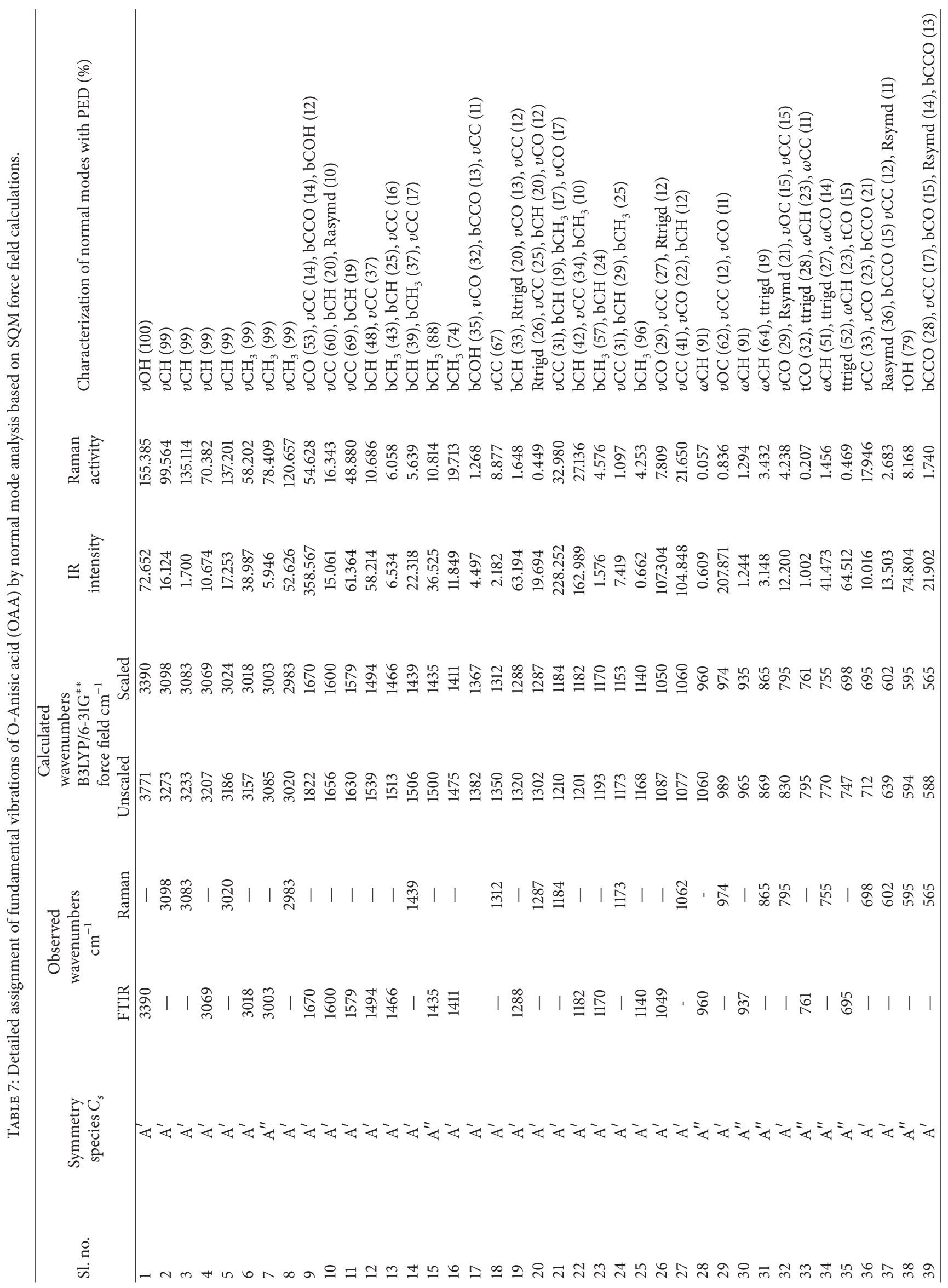




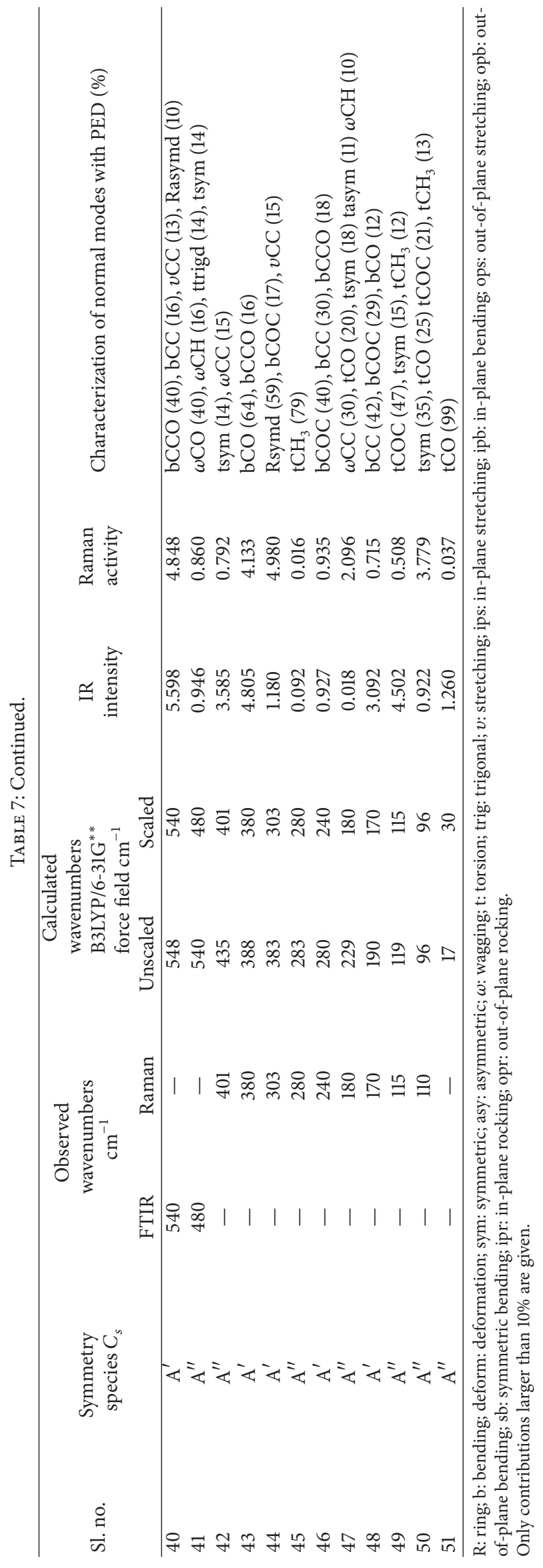




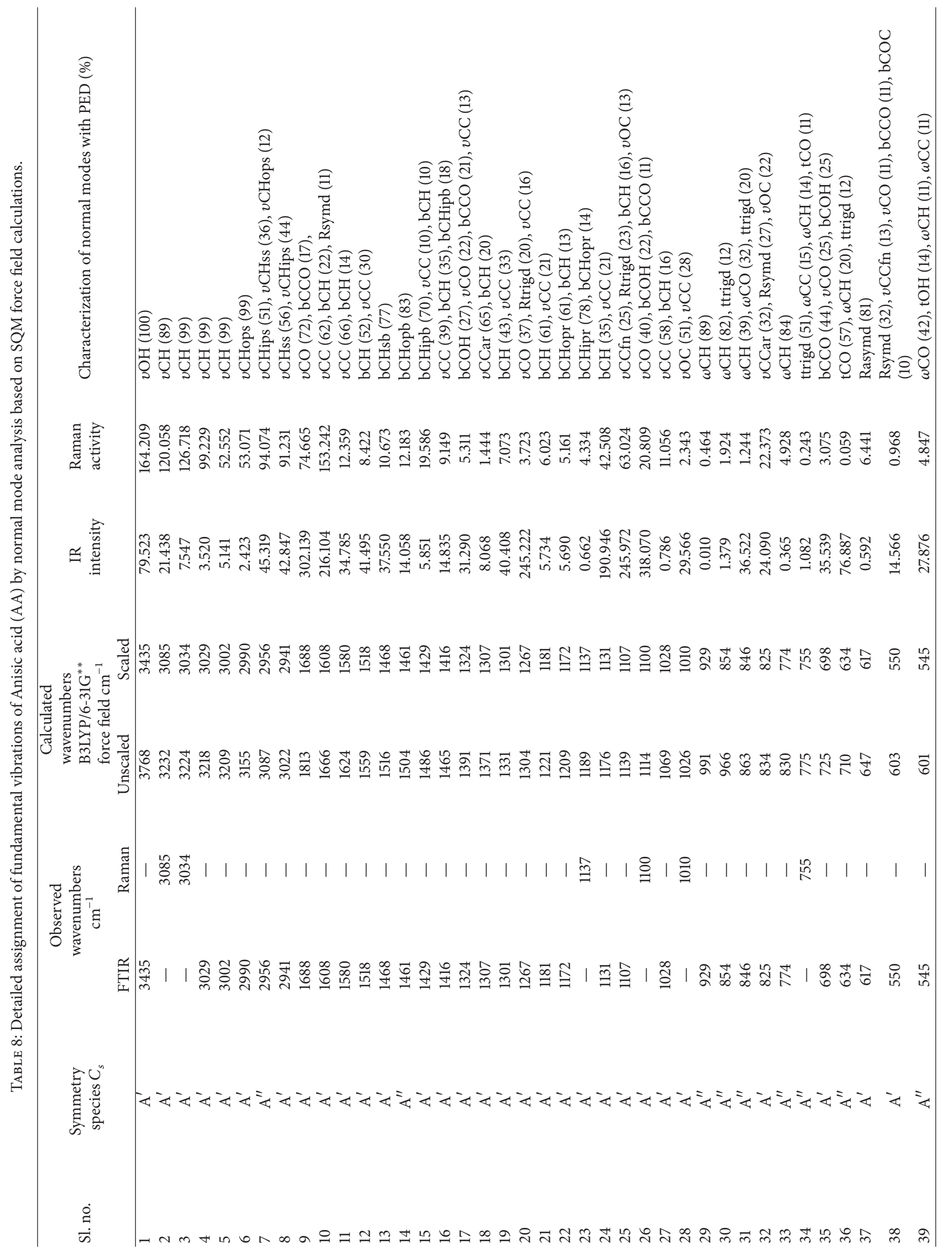




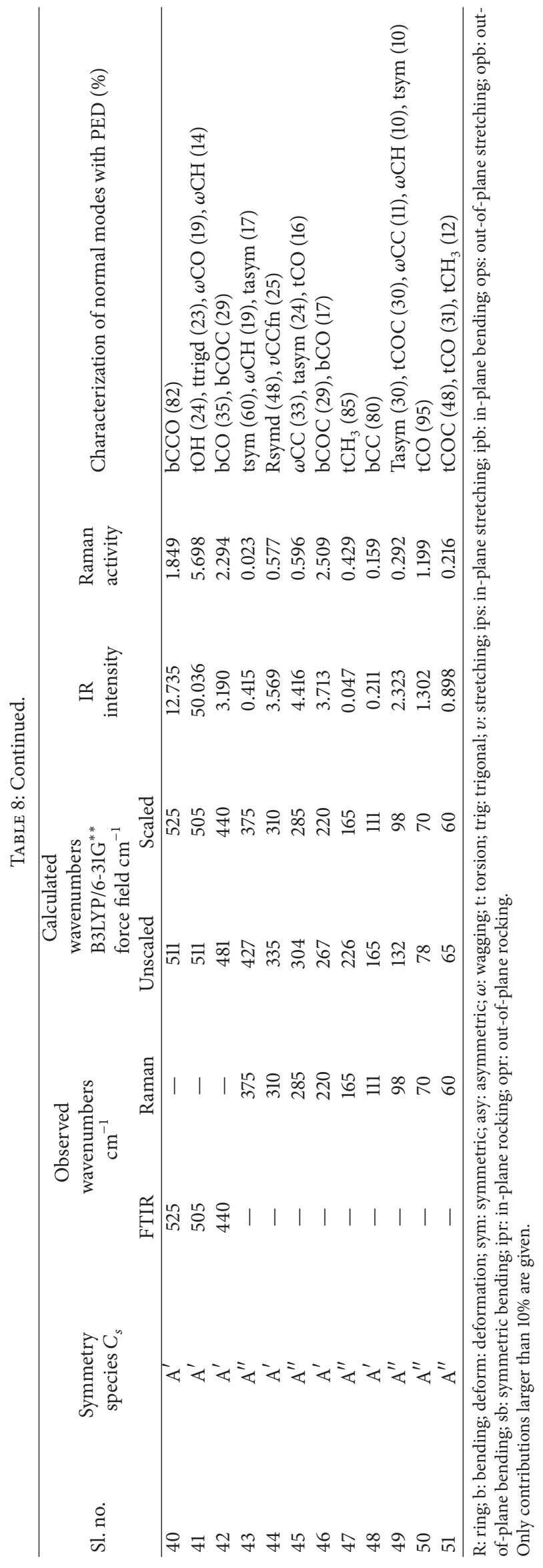




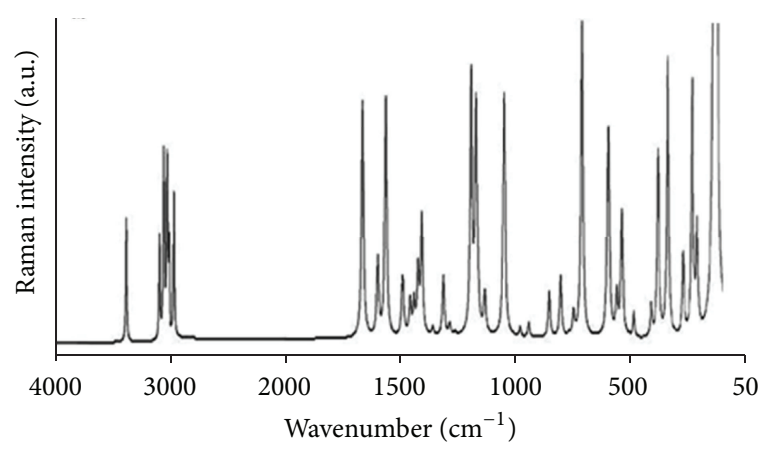

(a)

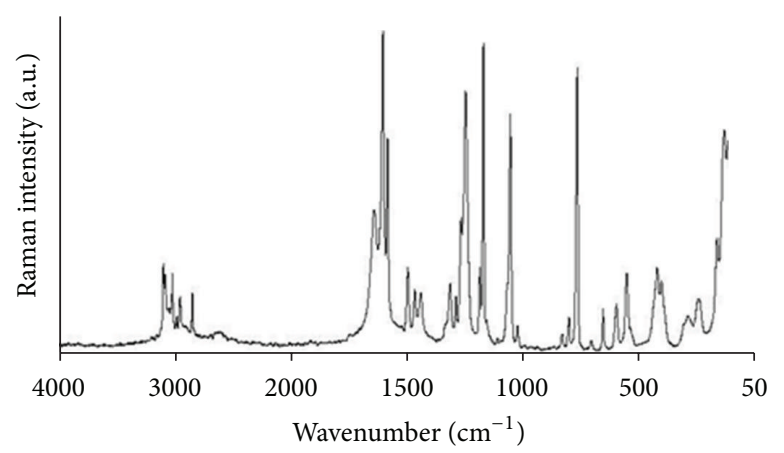

(b)

FIGURE 3: FT-Raman spectra of O-Anisic acid (a) observed and (b) calculated with B3LYP/6-31G**.

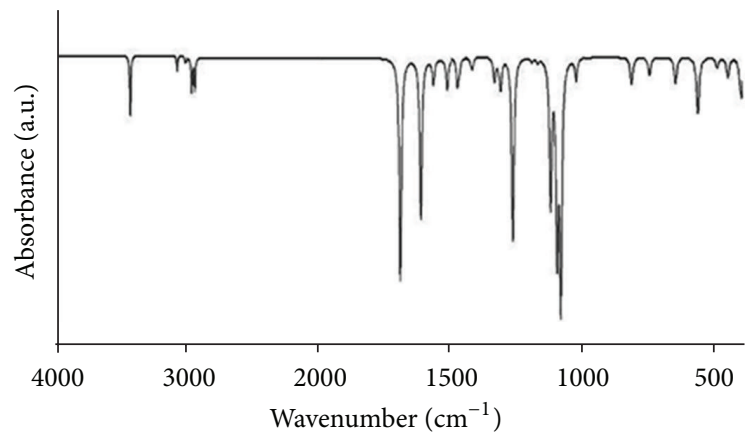

(a)

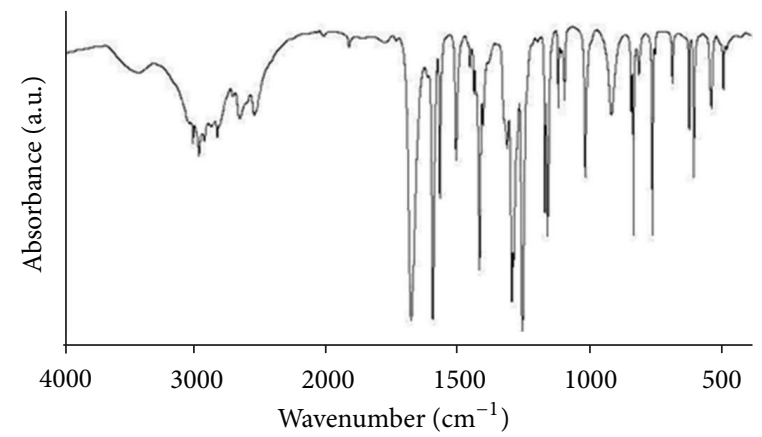

(b)

FIGURE 4: FTIR spectra of Anisic acid (a) observed and (b) calculated with B3LYP/6-31G***

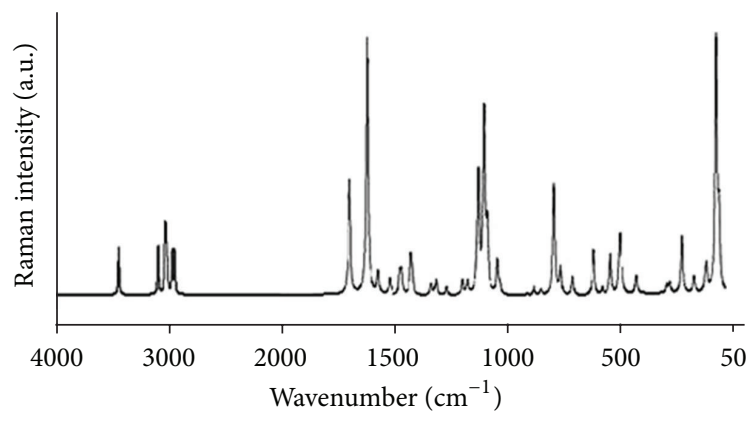

(a)

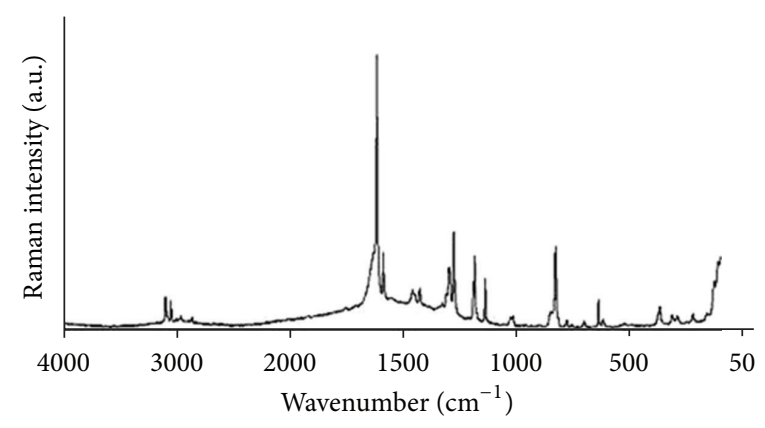

(b)

Figure 5: FT-Raman spectra of Anisic acid (a) observed and (b) calculated with B3LYP/6-31G**.

title molecules, all the hydrogen atoms have a net positive charge, in particular, the hydrogen atoms $\mathrm{H}(10)$ that have charge of 0.5047 and 0.5050 , respectively. The presence of large amounts of negative charge on oxygen and net positive charge on $\mathrm{H}(10)$ atoms may suggest the presence of intermolecular hydrogen bonding in the crystalline phase.

Highest occupied molecular orbital and lowest unoccupied molecular orbital are very important parameters for quantum chemistry. This is also used by the frontier electron density for predicting the most reactive position in $\pi$-electron systems and also explains several types of reaction in conjugated system [32]. The conjugated molecules are characterized by a small highest occupied molecular orbitallowest unoccupied molecular orbital (HOMO-LUMO) separation, which is the result of a significant degree of intermolecular charge transfer from the end-capping electrondonating groups to the efficient electron-acceptor groups through $\pi$ conjugated path [33]. Both the highest occupied molecular orbital and lowest unoccupied molecular orbital are the main orbitals that take part in chemical stability [34]. Energy difference between HOMO and LUMO orbital is called energy gap that is an important stability for structures which are given in Table 11. We performed an analysis of all the molecular orbitals involved, taking into consideration 
TABLE 9: Atomic charges for optimized geometry of O-Anisic acid (OAA) and Anisic acid (AA) obtained by B3LYP/6-31G ${ }^{* *}$ density functional calculations.

\begin{tabular}{lcc}
\hline Atoms $^{\mathrm{a}}$ & \multicolumn{2}{c}{ Mulliken } \\
& OAA & AA \\
\hline $\mathrm{C}_{1}$ & 0.0018 & 0.0373 \\
$\mathrm{C}_{2}$ & 0.3297 & -0.1002 \\
$\mathrm{C}_{3}$ & -0.1368 & -0.1219 \\
$\mathrm{C}_{4}$ & -0.0836 & 0.3612 \\
$\mathrm{C}_{5}$ & -0.0943 & -0.1394 \\
$\mathrm{C}_{6}$ & -0.1061 & -0.1118 \\
$\mathrm{C}_{7}$ & 0.5570 & 0.5445 \\
$\mathrm{O}_{8}$ & -0.4650 & -0.4848 \\
$\mathrm{O}_{9}$ & -0.5104 & -0.5064 \\
$\mathrm{H}_{10}$ & 0.3198 & 0.3217 \\
$\mathrm{O}_{11}\left(\mathrm{H}_{11}\right)$ & -0.4841 & 0.1203 \\
$\mathrm{C}_{12}\left(\mathrm{H}_{12}\right)$ & -0.0837 & 0.1021 \\
$\mathrm{H}_{13}\left(\mathrm{O}_{13}\right)$ & 0.1064 & -0.5111 \\
$\mathrm{H}_{14}\left(\mathrm{C}_{14}\right)$ & 0.1352 & -0.0831 \\
$\mathrm{H}_{15}$ & 0.1211 & 0.1099 \\
$\mathrm{H}_{16}$ & 0.0913 & 0.1302 \\
$\mathrm{H}_{17}$ & 0.0929 & 0.1246 \\
$\mathrm{H}_{18}$ & 0.0886 & 0.0913 \\
$\mathrm{H}_{19}$ & 0.1200 & 0.1155 \\
\hline
\end{tabular}

${ }^{\mathrm{a}}$ The atoms indicated in the parenthesis belong to AA.

TABLE 10: Natural atomic charges of O-Anisic acid (OAA) and Anisic acid (AA) calculations performed at the B3LYP/6-31G ${ }^{* *}$ level of theory.

\begin{tabular}{|c|c|c|}
\hline Atoms $^{\mathrm{a}}$ & OAA & AA \\
\hline $\mathrm{C}_{1}$ & -0.2176 & -0.2053 \\
\hline $\mathrm{C}_{2}$ & 0.3724 & -0.1746 \\
\hline $\mathrm{C}_{3}$ & -0.3284 & -0.2801 \\
\hline $\mathrm{C}_{4}$ & -0.1952 & 0.3443 \\
\hline $\mathrm{C}_{5}$ & -0.2720 & -0.3289 \\
\hline $\mathrm{C}_{6}$ & -0.1806 & -0.1748 \\
\hline $\mathrm{C}_{7}$ & 0.8091 & 0.8139 \\
\hline $\mathrm{O}_{8}$ & -0.5861 & -0.6102 \\
\hline $\mathrm{O}_{9}$ & -0.7295 & -0.7217 \\
\hline $\mathrm{H}_{10}$ & 0.5047 & 0.5050 \\
\hline $\mathrm{O}_{11}\left(\mathrm{H}_{11}\right)$ & -0.4921 & 0.2634 \\
\hline $\mathrm{C}_{12}\left(\mathrm{H}_{12}\right)$ & -0.3307 & 0.2544 \\
\hline $\mathrm{H}_{13}\left(\mathrm{O}_{13}\right)$ & 0.2070 & -0.5119 \\
\hline $\mathrm{H}_{14}\left(\mathrm{C}_{14}\right)$ & 0.2390 & -0.3300 \\
\hline $\mathrm{H}_{15}$ & 0.2070 & 0.2090 \\
\hline $\mathrm{H}_{16}$ & 0.2443 & 0.2352 \\
\hline $\mathrm{H}_{17}$ & 0.2426 & 0.2090 \\
\hline $\mathrm{H}_{18}$ & 0.2439 & 0.2449 \\
\hline $\mathrm{H}_{19}$ & 0.2621 & 0.2585 \\
\hline
\end{tabular}

${ }^{\mathrm{a}}$ The atoms indicated in the parenthesis belong to AA.

For numbering of atoms refer to Figures 1(a) and 1(b).

that orbital 40 is the HOMO and orbital 41 is the LUMO for OAA and AA, respectively.

Many organic molecules that contain conjugated $\pi$ electrons are characterized as hyperpolarisabilities and are analyzed by means of vibrational spectroscopy. The analysis
TABLE 11: Calculated quantum chemical parameters of $\mathrm{O}$-Anisic acid (OAA) and Anisic acid (AA) derivatives.

\begin{tabular}{lcc}
\hline Parameters & OAA & AA \\
\hline$E_{\text {HOMO }}$ & -0.227 & -0.231 \\
$E_{\text {LUMO }}$ & -0.041 & -0.036 \\
$\Delta E$ & 0.186 & 0.195 \\
$\chi$ & 0.134 & 0.133 \\
$\mathrm{H}$ & 0.093 & 0.097 \\
$\Sigma$ & 10.752 & 10.256 \\
\hline
\end{tabular}

TABLE 12: Calculated ${ }^{13} \mathrm{C}$ NMR chemical shifts (ppm) of O-Anisic acid (OAA) and Anisic acid (AA).

\begin{tabular}{lcccc}
\hline \multirow{2}{*}{ Carbon $^{\mathrm{a}}$} & \multicolumn{2}{c}{ Exp } & \multicolumn{2}{c}{ B3LYP/6-31G** } \\
& OAA & AA & OAA & AA \\
\hline $\mathrm{C}_{1}$ & 117.82 & 123.15 & 104.47 & 126.20 \\
$\mathrm{C}_{2}$ & 158.48 & 131.46 & 146.96 & 139.36 \\
$\mathrm{C}_{3}$ & 112.04 & 113.84 & 96.81 & 122.72 \\
$\mathrm{C}_{4}$ & 135.17 & 162.97 & 119.26 & 171.25 \\
$\mathrm{C}_{5}$ & 121.91 & 113.84 & 104.47 & 110.47 \\
$\mathrm{C}_{6}$ & 133.47 & 131.46 & 120.19 & 137.51 \\
$\mathrm{C}_{7}$ & 166.34 & 167.14 & 146.09 & 171.74 \\
$\mathrm{C}_{12}\left(\mathrm{C}_{14}\right)$ & 56.74 & 55.44 & 43.22 & 55.49 \\
\hline
\end{tabular}

${ }^{\mathrm{a}}$ The atoms indicated in the parenthesis belong to AA.

TABLE 13: Experimental and calculated ${ }^{1} \mathrm{H}$ NMR chemical shifts (ppm) of O-Anisic acid (OAA) and Anisic acid (AA).

\begin{tabular}{lcccc}
\hline \multirow{2}{*}{ Proton $^{\mathrm{a}}$} & \multicolumn{2}{c}{ Exp } & \multicolumn{2}{c}{ B3LYP/6-31G ** } \\
& OAA & AA & OAA & AA \\
\hline $\mathrm{H}_{10}$ & 10.30 & 13 & 11 & 11 \\
$\mathrm{H}_{13}, \mathrm{H}_{14}, \mathrm{H}_{15}\left(\mathrm{H}_{11}\right)$ & 4.066 & 7.914 & 3.932 & 8.405 \\
$\mathrm{H}_{16}\left(\mathrm{H}_{12}\right)$ & 7.08 & 7.027 & 6.831 & 7.147 \\
$\mathrm{H}_{17}\left(\mathrm{H}_{15}, \mathrm{H}_{16}, \mathrm{H}_{17}\right)$ & 7.56 & 3.836 & 7.570 & 3.824 \\
$\mathrm{H}_{18}$ & 7.10 & 7.027 & 7.069 & 6.673 \\
$\mathrm{H}_{19}$ & 8.13 & 7.914 & 3.932 & 8.217 \\
\hline a The atoms indicated in the parenthesis belong to AA.
\end{tabular}

of the wave function indicates that the electron absorption corresponds to the transition from the ground state to the first excited state and is mainly described by the one-electron excitation from the HOMO to the LUMO. The HOMO, of $\pi$ nature (i.e., aromatic ring), is delocalized over the whole C$\mathrm{C}$ bond. By contrast, the LUMO is located over the aromatic ring. Consequently, the HOMO-LUMO transition implies an electron density transfer to $\mathrm{COOH}$ and $\mathrm{OCH}_{3}$ group from the aromatic ring.

The theoretical basis for the new quantities lies in the density functional formalism [35]. Since molecular orbital (MO) theory is by far the most widely used by chemists, it is important to place $\chi$ and $\eta$ in a MO framework. It has already been shown [36] that the MO theory of the chemical bond contains the values of $\chi$ and $\eta$ for the bonding fragments. Hard molecules have a large HOMO-LUMO gap, and soft molecules have a small HOMO-LUMO gap. A small 


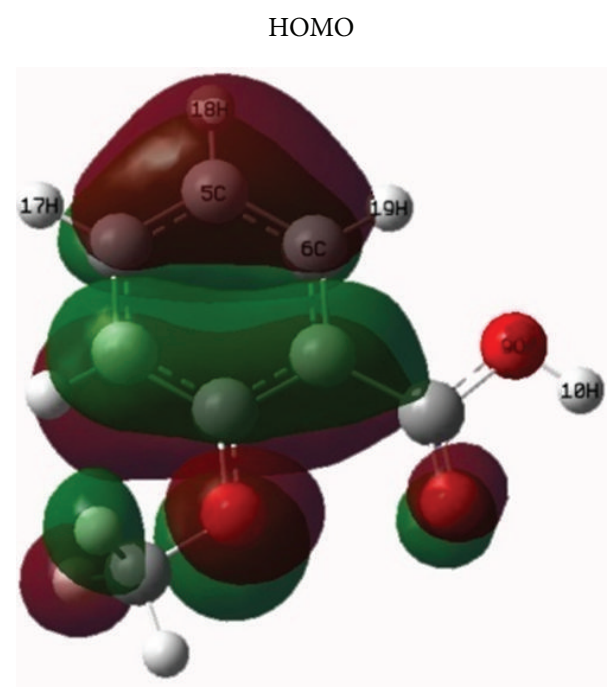

(a)

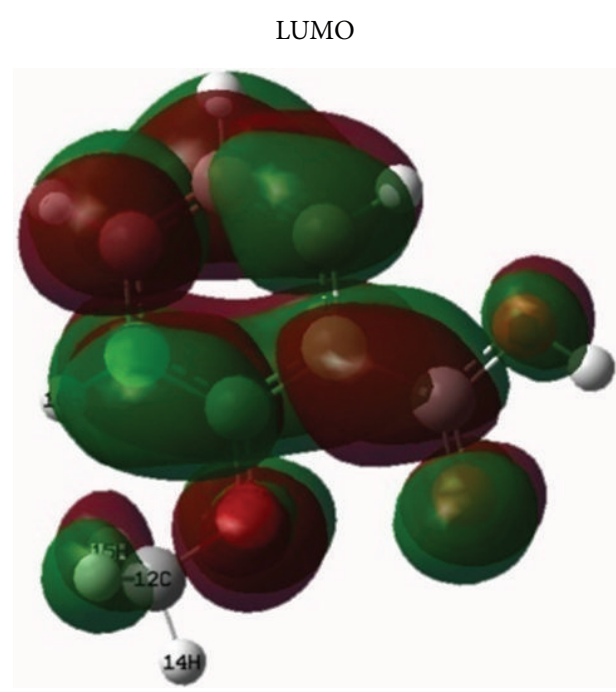

(b)

FIgURE 6: Contour surfaces of frontier molecular orbitals of O-Anisic acid.

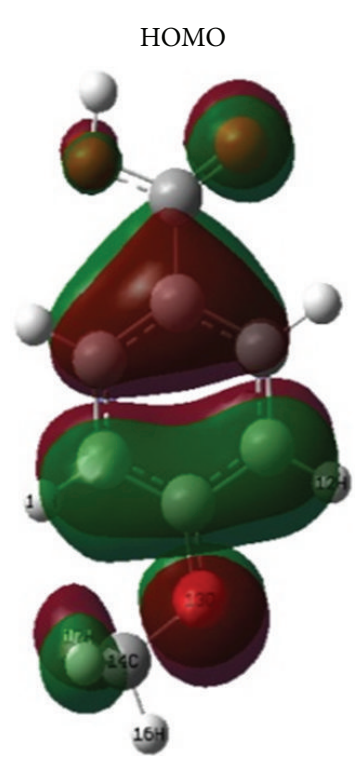

(a)

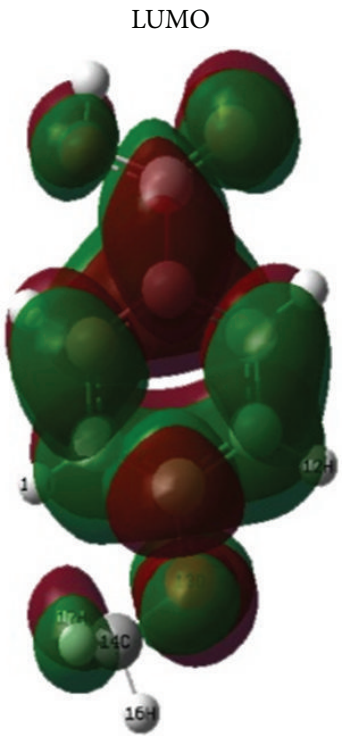

(b)

FIGURE 7: Contour surfaces of frontier molecular orbitals of Anisic acid.

HOMO-LUMO gap automatically means small excitation energies to the manifold of excited states. Therefore, soft molecules, with a small gap, will be more polarizable than hard molecules. High polarizability was the most characteristic property attributed to soft acids and bases. Energy gaps should be small for best bonding, or both molecules should be soft.

In the present study, the title compound AA is dynamically more stable due to the large energy gap. OAA is a soft molecule due to small energy gap. The Contour surfaces of the frontier molecular orbitals are sketched in Figures 6 and 7.
5.1. NMR Spectra. DFT methods treat the electronic energy as a function of the electron density of all electrons simultaneously and thus include electron correlation effect [37]. In this study, molecular structure of the OAA and AA was optimized by using B3LYP method in conjunction with 6$31 \mathrm{G}^{* *} \cdot{ }^{13} \mathrm{C}$ and ${ }^{1} \mathrm{H}$ chemical shift calculations of the title compounds have been made by using GIAO method and same basis set. The isotropic shielding values were used to calculate the isotropic chemical shifts $\delta$ with respect to tetramethylsilane (TMS). The isotropic chemical shifts are frequently used as an aid in identification of reactive ionic species. The B3LYP method allows calculating the shielding 


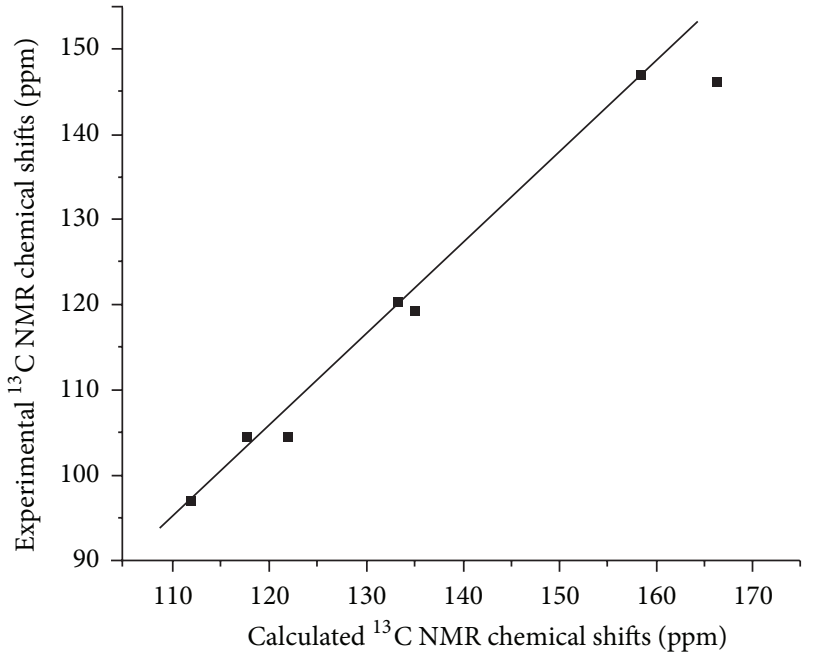

(a)

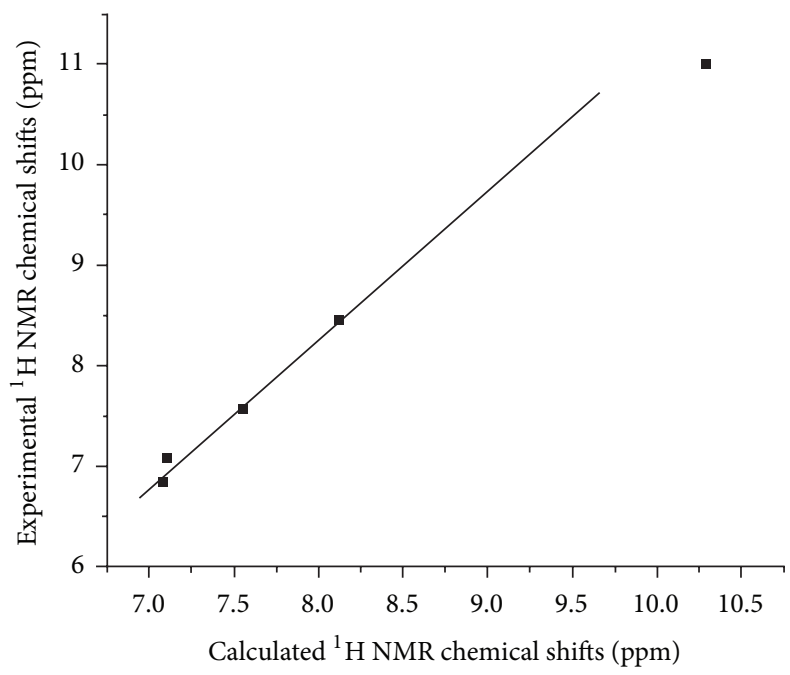

(b)

Figure 8: Plot of the calculated versus the experimental ${ }^{13} \mathrm{C}$ NMR and ${ }^{1} \mathrm{H}$ NMR chemical shifts (ppm) for O-Anisic acid.

constants with the proper accuracy, and the GIAO method is one of the most common approaches for calculating nuclear magnetic shielding tensors.

Theoretical and experimental chemical shifts of OAA and AA in ${ }^{1} \mathrm{H}$ and ${ }^{13} \mathrm{C}$ NMR spectra are gathered in Tables 12 and 13. The range of the ${ }^{13} \mathrm{C}$ NMR chemical shifts for a typical organic molecules usually is $>100 \mathrm{ppm}[38,39]$ and the accuracy ensures reliable interpretation of spectroscopic parameters. In the present study, the ${ }^{13} \mathrm{C}$ NMR chemical shifts in the ring are $>100 \mathrm{ppm}$, as they would be expected. The ${ }^{13} \mathrm{C}$ chemical shifts carbonyl carbons vary from 150 to $220 \mathrm{ppm}$. This depends on the decrease in electron donating or shielding ability of the attached atoms [40]. The $\mathrm{C}=\mathrm{O}$ groups of carboxylic acids and derivatives are in the range of 150-185 ppm [29].

Hydrogens bonded to an aromatic ring are strongly deshielded and absorb downfield. When the $\pi$-electrons enter the magnetic field, they circulate around the ring to generate a ring current. This produces a small induced magnetic field that reinforces the applied field outside the ring, resulting in aromatic protons being deshielded [41]. A related effect is observed for carboxylic acids. For these compounds, circulation of electrons in the double bonds produces induced magnetic field. These are responsible for the high chemical shift values of acid protons (H10). Carboxylic acids as stable hydrogen-bonded dimers in nonpolar solvents even at high dilution. The carboxylic proton therefore absorbs in a characteristically narrow range, 13.2 to 10.0 and is affected only slightly by concentration [29].

In a methyl group, a proton is covalently bonded to carbon, oxygen, or other atoms by a sigma bond. When placed in a strong magnetic field, the electrons of the sigma bond circulate to generate a small magnetic field which opposes the applied field. A nearby electronegative atom withdraws electron density from the neighbourhood of the proton, so that a smaller applied field is needed to cause the spin state of the proton to flip. The signal for a deshielded
TABLE 14: Theoretically computed energies (a.u.), zero-point vibrational energies $\left(\mathrm{kcal} \mathrm{mol}^{-1}\right)$, rotational constants $(\mathrm{GHz})$, entropies (cal mol ${ }^{-1} \mathrm{~K}^{-1}$ ), nuclear repulsion energy (Hartrees), and dipole moment (Debye) for OAA and AA.

\begin{tabular}{lcc}
\hline \multirow{2}{*}{ Parameters } & \multicolumn{2}{c}{ B3LYP/6-31G ${ }^{* *}$} \\
\hline Zero-point energy & 93.06056 & AA \\
Rotational constants & 1.39942 & 3.444066 \\
& 1.14384 & 0.56752 \\
Entropy & 0.63193 & 0.48875 \\
Total & & \\
Translational & 99.243 & 97.126 \\
Rotational & 40.967 & 40.967 \\
Vibrational & 30.142 & 30.199 \\
Dipole moment & 28.134 & 25.960 \\
Nuclear repulsion energy & 2.4181 & 3.5822 \\
\hline
\end{tabular}

proton ( 1 surrounded by less electron density) is observed to be more downfield than the signals for protons that are not deshielded by electronegative atoms [40]. The chemical shift value of $\mathrm{C7}$ (OAA and AA) has bigger value than the other carbons due to the electronegative property of oxygen atom.

The linear correlations between calculated and experimental data of ${ }^{13} \mathrm{C}$ NMR and ${ }^{1} \mathrm{H}$ NMR spectra are determined as 0.9 , and 1.0 for OAA and 0.9 , and 0.9 for AA, respectively. There is an excellent linear relationship between experimental and computed results which are shown in Figures 8 and 9.

\section{Thermodynamic Properties}

Several calculated thermodynamical parameters are presented in Table 14 for OAA and AA, respectively. Scale factors have been recommended [42] for an accurate prediction in 


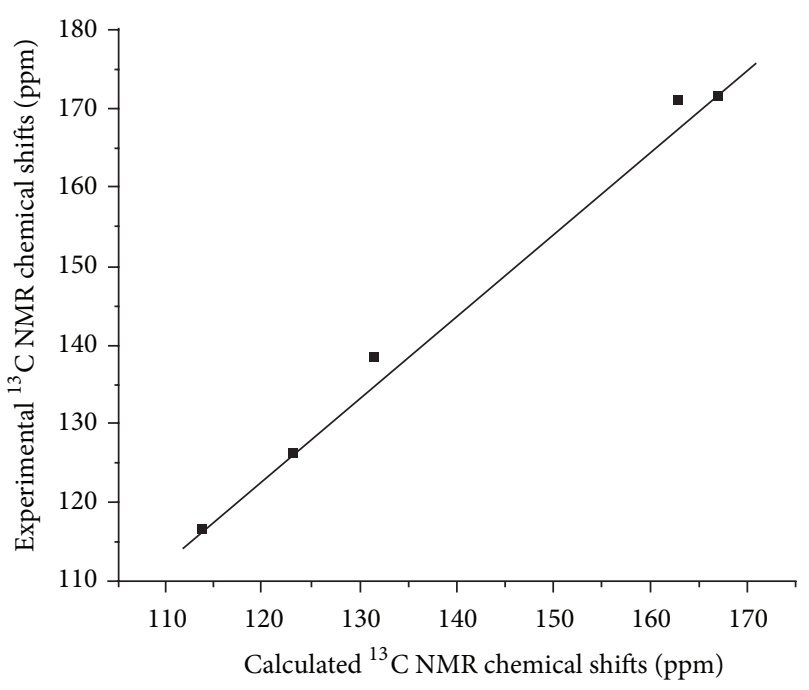

(a)

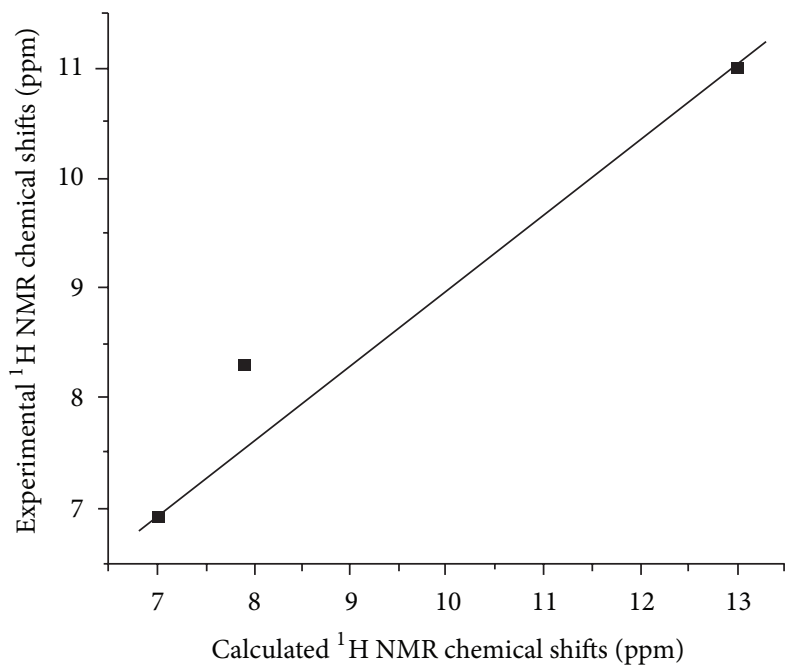

(b)

FIgURE 9: Plot of the calculated versus the experimental ${ }^{13} \mathrm{C}$ NMR and ${ }^{1} \mathrm{H}$ NMR chemical shifts (ppm) for Anisic acid.

determining the zero-point vibration energies (ZPVE) and the entropy $S_{\mathrm{vib}}(T)$. The total energies and the change in the total entropy at room temperature using $\mathrm{B} 3 \mathrm{LYP} / 6-31 \mathrm{G}^{* *}$ method are presented.

\section{Conclusion}

Attempts have been made in the present work for the molecular parameters and frequency assignments for the compounds OAA and AA from the FTIR and FT-Raman spectra. The equilibrium geometries and harmonic and anharmonic frequencies for the title compounds were determined and analyzed at DFT level of theory utilizing $6-31 \mathrm{G}^{* *}$ basis set. The assignments of most of the fundamentals of the title compounds provided in this work are quite comparable. The excellent agreement of the calculated and observed vibrational spectra reveals the advantages of a smaller basis set for quantum chemical calculations. HOMO and LUMO energy gap explains the eventual charge transfer interactions taking place within the molecule. The experimental and theoretical investigation of the title compounds have been performed successfully by using ${ }^{1} \mathrm{H}$ and ${ }^{13} \mathrm{C}$ NMR. The various modes of vibrations were unambiguously assigned on the basis of the result of the PED output obtained from normal coordinate analysis. These studies confirm the presence of $\mathrm{COOH}$ and $\mathrm{OCH}_{3}$ group. Dimeric molecules are held together by hydrogen bridges between carbonyl groups. The obtained data and simulations both show the way to the characterization of the molecules and help in spectra studies in the future.

\section{References}

[1] G. Melentyeva and L. Antonova, Pharmaceutical Chemistry, Mir Publishers, Moscow, Russia, 1988.
[2] "o-Anisic acid(579-75-9): catalog of chemical suppliers," http:// www.chemexper.com/chemicals/supplier/cas/579-75-9.html.

[3] B. A. Hess Jr., L. J. Schaad, P. Carsky, and R. Zaharaduick, "Ab initio calculations of vibrational spectra and their use in the identification of unusual molecules," Chemical Reviews, vol. 86, no. 4, pp. 709-730, 1986.

[4] P. Pulay, X. Zhou, and G. Forgarasi, in Recent Experimental and Computational Advances in Molecular Spectroscopy, R. Fausto and R. Fransto, Eds., vol. 406 of NATO ASI Series, p. 99, Kluwer, Dordrecht, Netherlands, 1993.

[5] P. Pulay, G. Fogarasi, G. Pongor, J. E. Boggs, and A. Vargha, "Combination of theoretical ab initio and experimental information to obtain reliable harmonic force constants. Scaled Quantum Mechanical (SQM) force fields for glyoxal, acrolein, butadiene, formaldehyde, and ethylene," Journal of the American Chemical Society, vol. 105, no. 24, pp. 7037-7047, 1983.

[6] C. E. Blom and C. Altona, "Application of self-consistent-field ab initio calculations to organic molecules," Molecular Physics, vol. 31, no. 5, pp. 1377-1391, 1976.

[7] G. Fogarasi and P. Pulay, in Vibrational Spectra and Structure, J. R. Durig, Ed., vol. 14, Elsevier, Amsterdam, Netherlands, 1985.

[8] G. Fogarasi, "Recent developments in the method of SQM force fields with application to 1-methyladenine," Spectrochimica Acta A, vol. 53, no. 8, pp. 1211-1224, 1997.

[9] G. R. de Mare, N. Yu. Panchenko, and W. Ch. Bock, "An MP2/6$31 \mathrm{G} * / / \mathrm{MP} 2 / 6-31 \mathrm{G} *$ vibrational analysis of s-trans- and s-cisacryloyl fluoride, $\mathrm{CH} 2=\mathrm{CH}-\mathrm{CF}=\mathrm{O}$," The Journal of Physical Chemistry, vol. 98, no. 5, pp. 1416-1420, 1994.

[10] G. Pongor, P. Pulay, G. Fogarasi, and J. E. Boggs, "Theoretical prediction of vibrational spectra. 1. The in-plane force field and vibrational spectra of pyridine," Journal of the American Chemical Society, vol. 106, no. 10, pp. 2765-2769, 1984.

[11] Y. Yamakitu and M. Tasumi, "Vibrational analyses of pbenzoquinodimethane and p-benzoquinone based on ab initio Hartree-Fock and second-order Moller-Plesset calculations," The Journal of Physical Chemistry, vol. 99, no. 21, pp. 8524-8534, 1995. 
[12] M. Karabacak, A. Çoruh, and M. Kurt, "FT-IR, FT-Raman, NMR spectra, and molecular structure investigation of 2,3dibromo-N-methylmaleimide: a combined experimental and theoretical study," Journal of Molecular Structure, vol. 892, no. 1-3, pp. 125-131, 2008.

[13] M. S. Masoud, M. K. Awad, M. A. Shaker, and M. M. T. ElTahawy, "The role of structural chemistry in the inhibitive performance of some aminopyrimidines on the corrosion of steel," Corrosion Science, vol. 52, no. 7, pp. 2387-2396, 2010.

[14] M. J. Frisch, G. W. Trucks, H. B. Schlegel et al., Gaussian 03 Revision B.4, Gaussian Inc, Pittsburgh, Pa, USA, 2003.

[15] P. L. Polavarapu, "Ab initio vibrational Raman and Raman optical activity spectra," Journal of Physical Chemistry, vol. 94, no. 21, pp. 8106-8112, 1990.

[16] G. Keresztury, S. Holly, J. Varga, G. Besenyei, A. Wang, and J. R. Durig, "Vibrational spectra of monothiocarbamates-II. IR and Raman spectra, vibrational assignment, conformational analysis and ab initio calculations of S-methyl-N,Ndimethylthiocarbamate," Spectrochimica Acta A, vol. 49, no. 1314, pp. 2007-2017, 1993.

[17] G. Keresztury, "Raman spectroscopy: theory," in Handbook of Vibrational Spectroscopy, J. M. Chalmers and P. R. Griffths, Eds., vol. 1, p. 71, John Wiley and Sons, 2002.

[18] R. G. Parr, R. A. Donnelly, M. Levy, and W. E. Palke, "Electronegativity: the density functional viewpoint," The Journal of Chemical Physics, vol. 68, no. 8, pp. 3801-3807, 1977.

[19] R. G. Parr and R. G. Pearson, "Absolute hardness: companion parameter to absolute electronegativity," Journal of the American Chemical Society, vol. 105, no. 26, pp. 7512-7516, 1983.

[20] R. G. Pearson, "Absolute electronegativity and hardness: application to inorganic chemistry," Inorganic Chemistry, vol. 27, no. 4, pp. 734-740, 1988.

[21] P. Geerlings, F. De Proft, and W. Langenaeker, "Conceptual density functional theory," Chemical Reviews, vol. 103, no. 5, pp. 1793-1873, 2003.

[22] R. Ditchfield, "Molecular orbital theory of magnetic shielding and magnetic susceptibility," Journal of Physical Chemistry, vol. 56, no. 11, article 5688, 4 pages, 1972.

[23] K. Wolinski, J. F. Hilton, and P. Pulay, "Efficient implementation of the gauge-independent atomic orbital method for NMR chemical shift calculations," Journal of the American Chemical Society, vol. 112, no. 23, pp. 8251-8260, 1990.

[24] M. Kurt, M. Yurdakul, and Ş. Yurdakul, "Molecular structure and vibrational spectra of 3-chloro-4-methyl aniline by density functional theory and ab initio Hartree-Fock calculations," Journal of Molecular Structure, vol. 711, no. 1-3, pp. 25-32, 2004.

[25] D. Steele and D. H. Whiffen, "The vibration frequencies of pentafluorobenzene," Spectrochimica Acta, vol. 16, no. 3, pp. 368-375, 1960.

[26] D. N. Sathyanarayanan, Vibrational Spectroscopy Theory and Application, New Age International publishers, New Delhi, India, 1996.

[27] L. D. S. Yadav, Organic Spectroscopy, Springer, New Delhi, India, 2004.

[28] J. Mohan, Organic Spectroscopy, Principles and Applications, Narosa Publishing House, New Delhi, 2nd edition, 2009.

[29] R. M. Silverstein, G. C. Bassler, and T. C. Morrill, Spectrometric Identification of Organic Compounds, John Wiley \& Sons, New York, NY, USA, 1981.

[30] G. Socrates, Infrared Characteristic Group Frequencies, Wiley, New York, NY, USA, 1980.
[31] R. S. Mulliken, "Electronic population analysis on LCAO-MO molecular wave functions," The Journal of Chemical Physics, vol. 23, no. 10, pp. 1833-1840, 1955.

[32] K. Fukuli, T. Yonezawa, and H. Shingu, "A molecular orbital theory of reactivity in aromatic hydrocarbons," Journal of Physical Chemistry, vol. 20, no. 4, article 722, 4 pages, 1952.

[33] C. H. Choi and M. Kertesz, "Conformational information from vibrational spectra of styrene, trans-stilbene, and cis-stilbene," Journal of Physical Chemistry A, vol. 101, no. 20, pp. 3823-3831, 1997.

[34] S. Gunasekaran, R. Arun Balaji, S. Kumaresan, G. Anand, and S. Srinivasan, "Experimental and theoretical investigations of spectroscopic properties of N-acetyl-5-methoxytryptamine," Canadian Journal of Analytical Sciences and Spectroscopy, vol. 53, no. 4, pp. 149-162, 2008.

[35] P. Hohenberg and W. Kohn, "Inhomogeneous electron gas," Physical Review, vol. 136, no. 3, pp. B864-B871, 1964.

[36] R. G. Pearson, "Absolute electronegativity and absolute hardness of Lewis acids and bases," Journal of the American Chemical Society, vol. 107, no. 24, pp. 6801-6806, 1985.

[37] D. Avci, Y. Atalay, M. Sekerci, and M. Dincer, "Molecular structure and vibrational and chemical shift assignments of 3-(2Hydroxyphenyl)-4-phenyl-1H-1,2,4-triazole-5-(4H)-thione by DFT and ab initio HF calculations," Spectrochimica Acta A, vol. 73, no. 1, pp. 212-217, 2009.

[38] H. O. Kalinowski, S. Berger, and S. Braun, Carbon13 NMR Spectroscopy, John Wiley \& Sons, Chichester, UK, 1988.

[39] K. Pihlaja and E. Kleinpeter, Carbon-13 NMR Chemical Shifts in Structural and Sterochemical Analysis, VCH Publishers, Deerfield Beach, Fla, USA, 1994.

[40] P. S. Kalsi, Spectroscopy of Organic Compounds, New Age International, 2004.

[41] A. F. Parsons, Keynotes in Organic Chemistry, Blackwell Publishing, Oxford, UK, 2003.

[42] M. A. Palafox, "Scaling factors for the prediction of vibrational spectra. I: benzene molecule," International Journal of Quantum Chemistry, vol. 77, no. 3, pp. 661-684, 2000. 

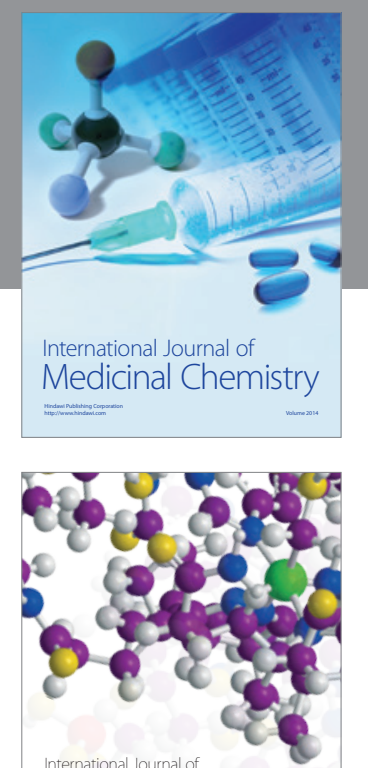

\section{Carbohydrate} Chemistry

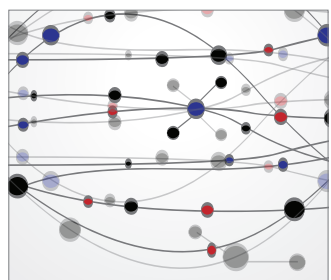

The Scientific World Journal
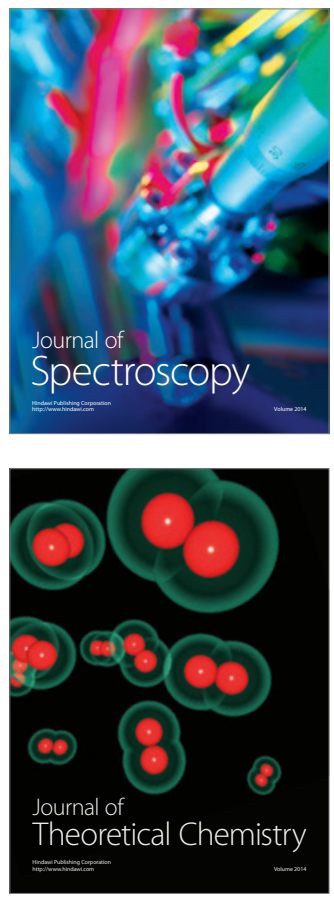
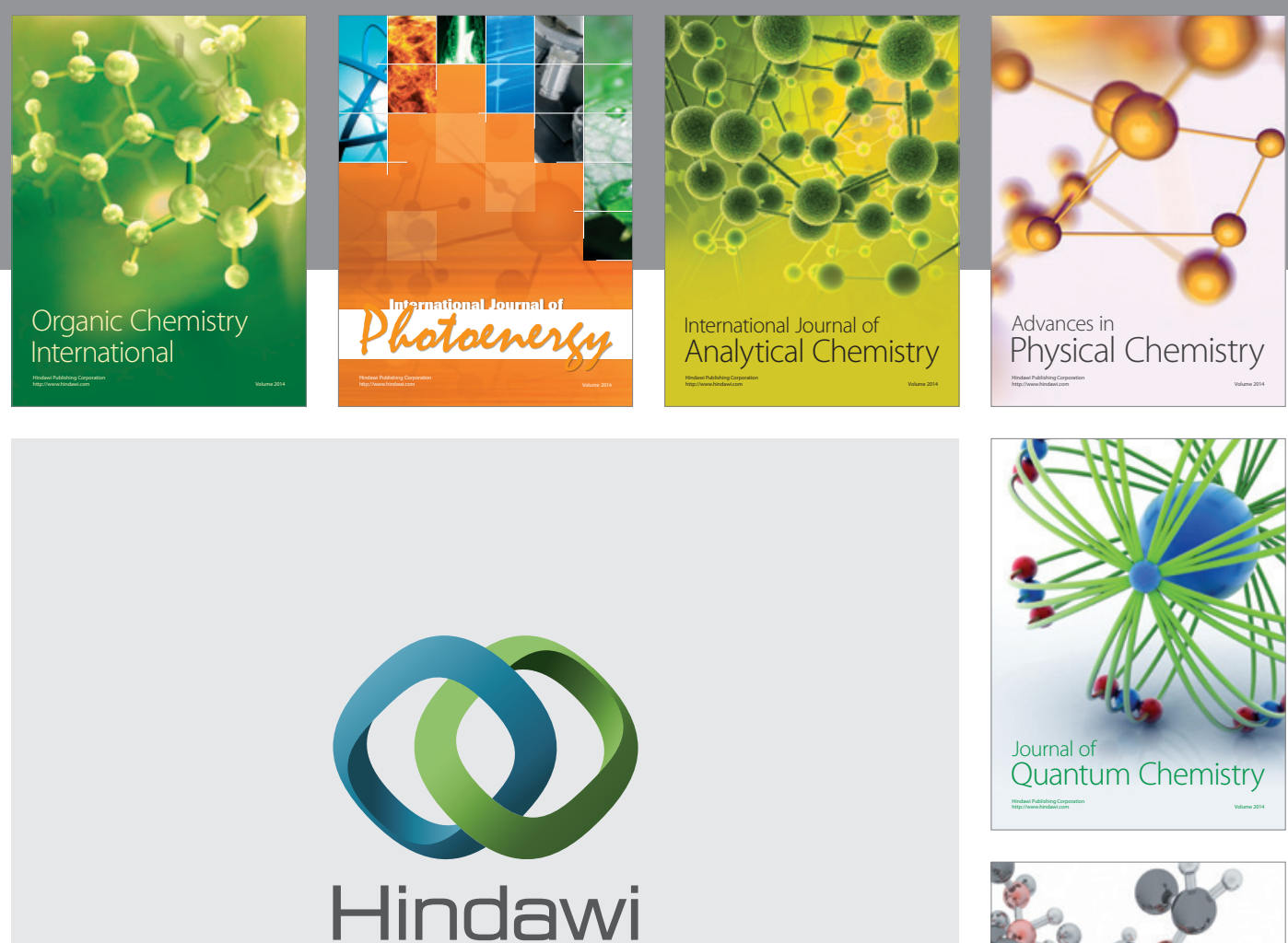

Submit your manuscripts at

http://www.hindawi.com

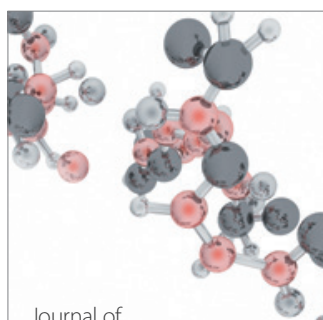

Analytical Methods

in Chemistry

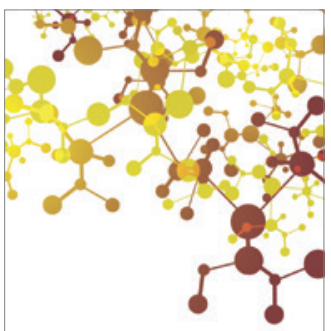

Journal of

Applied Chemistry

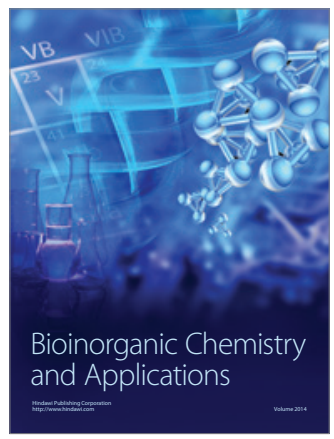

Inorganic Chemistry
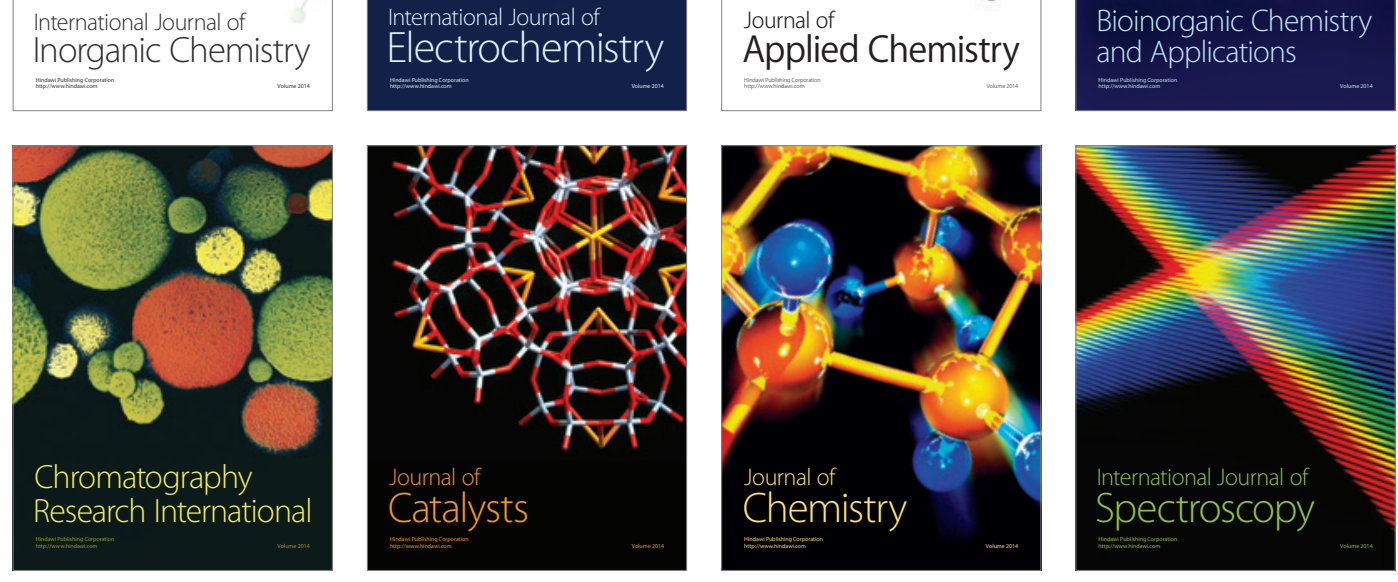